\title{
On the role of circulation and mixing in the ventilation of oxygen minimum zones with a focus on the eastern tropical North Atlantic
}

\author{
P. Brandt ${ }^{1}$, H. W. Bange ${ }^{1}$, D. Banyte ${ }^{1}$, M. Dengler ${ }^{1}$, S.-H. Didwischus ${ }^{1}$, T. Fischer ${ }^{1}$, R. J. Greatbatch ${ }^{1}$, J. Hahn ${ }^{1}$, \\ T. Kanzow ${ }^{1, *}$, J. Karstensen ${ }^{1}$, A. Körtzinger ${ }^{1}$, G. Krahmann ${ }^{1}$, S. Schmidtko ${ }^{1}$, L. Stramma ${ }^{1}$, T. Tanhua ${ }^{1}$, and \\ M. Visbeck ${ }^{1}$ \\ ${ }^{1}$ GEOMAR Helmholtz-Zentrum für Ozeanforschung Kiel, Kiel, Germany \\ *now at: Alfred-Wegener-Institut Helmholtz-Zentrum für Polar- und Meeresforschung, Bremerhaven, Germany
}

Correspondence to: P. Brandt (pbrandt@geomar.de)

Received: 17 July 2014 - Published in Biogeosciences Discuss.: 7 August 2014

Revised: 8 December 2014 - Accepted: 16 December 2014 - Published: 27 January 2015

\begin{abstract}
Ocean observations are analysed in the framework of Collaborative Research Center 754 (SFB 754) "ClimateBiogeochemistry Interactions in the Tropical Ocean" to study (1) the structure of tropical oxygen minimum zones (OMZs),

(2) the processes that contribute to the oxygen budget, and

(3) long-term changes in the oxygen distribution. The OMZ of the eastern tropical North Atlantic (ETNA), located between the well-ventilated subtropical gyre and the equatorial oxygen maximum, is composed of a deep OMZ at about $400 \mathrm{~m}$ in depth with its core region centred at about $20^{\circ} \mathrm{W}$, $10^{\circ} \mathrm{N}$ and a shallow $\mathrm{OMZ}$ at about $100 \mathrm{~m}$ in depth, with the lowest oxygen concentrations in proximity to the coastal upwelling region off Mauritania and Senegal. The oxygen budget of the deep OMZ is given by oxygen consumption mainly balanced by the oxygen supply due to meridional eddy fluxes (about $60 \%$ ) and vertical mixing (about $20 \%$, locally up to $30 \%$ ). Advection by zonal jets is crucial for the establishment of the equatorial oxygen maximum. In the latitude range of the deep OMZ, it dominates the oxygen supply in the upper 300 to $400 \mathrm{~m}$ and generates the intermediate oxygen maximum between deep and shallow OMZs. Water mass ages from transient tracers indicate substantially older water masses in the core of the deep OMZ (about 120-180 years) compared to regions north and south of it. The deoxygenation of the ETNA OMZ during recent decades suggests a substantial imbalance in the oxygen budget: about $10 \%$ of the oxygen consumption during that period was not balanced by ventilation. Long-term oxygen observations show variability on interannual, decadal and multidecadal timescales that can partly be attributed to circulation changes. In compar-
\end{abstract}

ison to the ETNA OMZ, the eastern tropical South Pacific OMZ shows a similar structure, including an equatorial oxygen maximum driven by zonal advection but overall much lower oxygen concentrations approaching zero in extended regions. As the shape of the OMZs is set by ocean circulation, the widespread misrepresentation of the intermediate circulation in ocean circulation models substantially contributes to their oxygen bias, which might have significant impacts on predictions of future oxygen levels.

\section{Introduction}

The oceanic oxygen distribution is generally characterised by slightly supersaturated oxygen levels in the surface layer, an intermediate oxygen minimum, and higher oxygen levels at depth. This vertical structure is a consequence of the delicate balance between the supply of oxygen through ventilation and circulation, oxygen production by photosynthesis, and oxygen consumption by remineralisation of sinking organic matter. The horizontal distribution of oxygen shows major large-scale open ocean subsurface oxygen minimum zones (OMZs) in the eastern parts of the tropical Atlantic and Pacific oceans as well as in the northern Indian Ocean. By analysing a combination of historical and modern observations, an expansion and intensification of OMZs in the tropical oceans has been detected (Stramma et al., 2008b). However, numerical simulations with global or regional models are not able consistently to reproduce such trends and thus up 


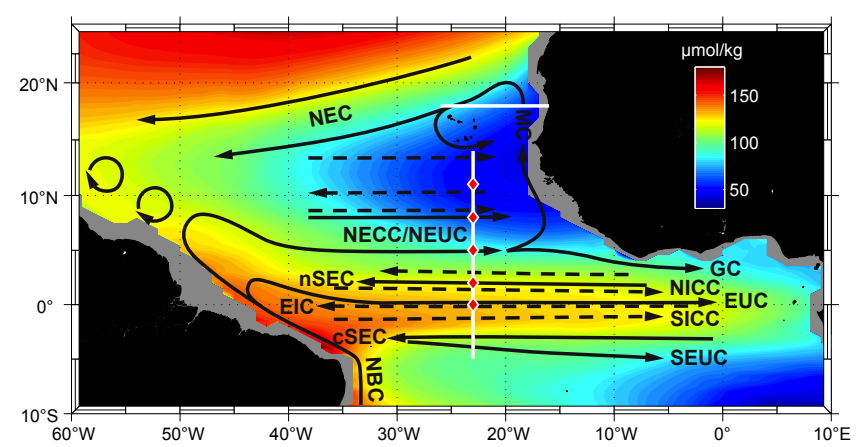

Figure 1. Oxygen concentration $\left(\mu \mathrm{mol} \mathrm{kg}{ }^{-1}\right)$ in the tropical Atlantic at $\sigma_{\theta}=27.1 \mathrm{~kg} \mathrm{~m}^{-3}$ (close to the deep oxygen minimum) as obtained from the MIMOC climatology (Schmidtko et al., 2013) with circulation schematic superimposed. Surface and thermocline current branches shown (black solid arrows) are the North Equatorial Current (NEC), the Mauritania Current (MC), the northern and central branches of the South Equatorial Current (nSEC and cSEC), the North Equatorial Countercurrent (NECC), the Guinea Current (GC), the North Brazil Current (NBC), the North and South Equatorial undercurrents (NEUC and SEUC), and the Equatorial Undercurrent (EUC). Intermediate current branches shown (black dashed arrows) are the North and South Intermediate countercurrents (NICC and SICC) or "flanking jets", and the Equatorial Intermediate Current (EIC). The $23^{\circ} \mathrm{W}$ and $18^{\circ} \mathrm{N}$ repeat sections are marked by white lines, mooring positions by red diamonds.

to now have failed to provide an explanation for the observed oxygen trends in the tropical ocean (Stramma et al., 2012).

OMZs in the tropical Atlantic were first identified by analysing hydrographic data from the German Meteor expedition from 1925 to 1927 (Wattenberg, 1938). This data set revealed the existence of OMZs in both hemispheres of the eastern tropical Atlantic at depths between 300 and $700 \mathrm{~m}$, situated equatorward of the subtropical gyres and separated by an equatorial oxygen maximum. Based on data, including those from the German Meteor expedition, and theoretical considerations, Wyrtki (1962) concluded that the boundaries of these OMZs are set by advection with the lowest oxygen levels occurring in almost stagnant water bodies. A plausible theory of thermocline ventilation was delivered by Luyten et al. (1983b). The basis of their theory is of an ocean forced by subtropical Ekman pumping and otherwise obeying circulation pathways that are governed by potential vorticity conservation. This theory explains the existence of non-ventilated, near-stagnant shadow zones in the eastern tropics. The remaining slow ventilation of such shadow zones, which under the assumption of steady state is required to balance oxygen consumption, is expected to be the consequence of lateral fluxes of oxygen from oxygen-rich water masses of the subtropics as well as due to diapycnal oxygen fluxes from oxygen-rich layers above and below the thermocline of the OMZs.

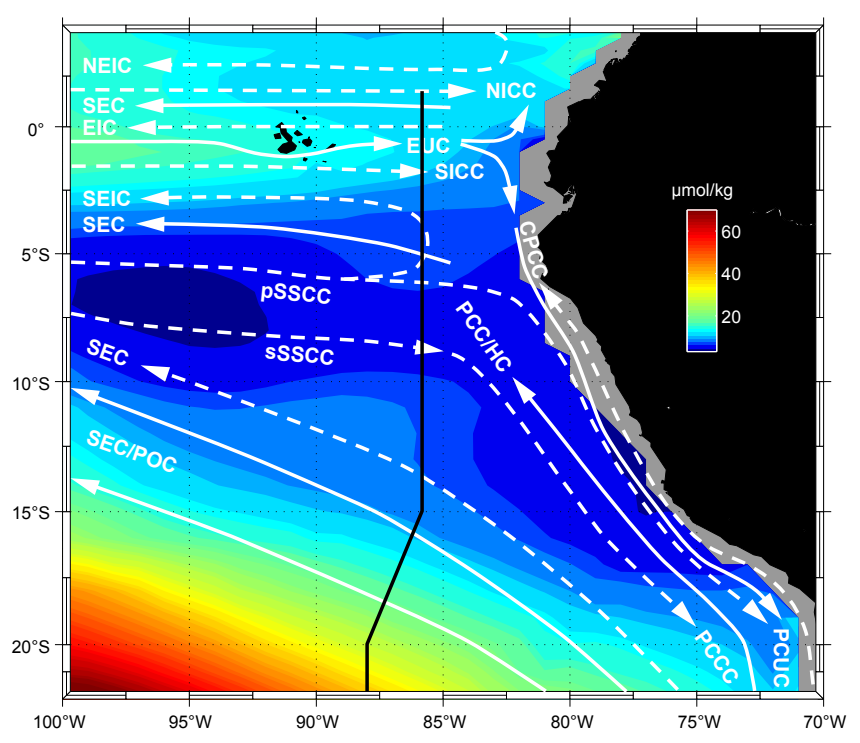

Figure 2. Oxygen concentration $\left(\mu \mathrm{mol} \mathrm{kg}{ }^{-1}\right)$ in the eastern tropical Pacific at $\sigma_{\theta}=26.8 \mathrm{~kg} \mathrm{~m}^{-3}$ (close to the deep oxygen minimum) as obtained from the MIMOC climatology (Schmidtko et al., 2013) with circulation schematic superimposed. Current bands displayed are, for the surface layer (white solid arrows), the South Equatorial Current (SEC), the Equatorial Undercurrent (EUC), the Peru-Chile or Humboldt Current (PCC/HC), the Peru Oceanic Current (POC), and for the thermocline layer (white dashed arrows), the North Equatorial Intermediate Current (NEIC), the North Intermediate Countercurrent (NICC), the Equatorial Intermediate Current (EIC), the South Intermediate Countercurrent (SICC), the primary and secondary Southern Subsurface countercurrents (pSSCC, sSSCC), the deeper layer of the SEC, the Chile-Peru Coastal Current (CPCC), the Peru-Chile Undercurrent (PCUC) and the PeruChile Countercurrent (PCCC). The location of the $\sim 86^{\circ} \mathrm{W}$ section is marked by the black line .

The near-surface layers (upper $\sim 250 \mathrm{~m}$ ) of the tropical oceans are characterised by the presence of energetic zonal current bands. In the Atlantic below that layer, substantial mean zonal currents are also found, particularly in the depth range of the OMZs (Fig. 1). Close to the Equator, the strongest intermediate currents are observed with eastward flow at $2^{\circ} \mathrm{N}$ and $2^{\circ} \mathrm{S}$ and westward flow in between. The eastward current bands have been found to ventilate the central and eastern equatorial regions with oxygen-rich waters from the western boundary (Tsuchiya et al., 1992; Schott et al., 1995, 1998). Together with time-varying equatorial jets they produce an equatorial oxygen maximum at intermediate depths (Brandt et al., 2012). Further poleward alternating zonal jets are present at intermediate depths including the latitude range of the OMZs. Their strengths have been quantified using subsurface drift trajectories from floats (Maximenko et al., 2005; Ollitrault et al., 2006) and repeated shipboard sections (Brandt et al., 2010). Such currents have been reproduced by idealised process modelling (Ménesguen et al., 2009; Ascani et al., 2010; Qiu et al., 2013), 
but are typically not found (or are unrealistically weak) in ocean circulation models. They contribute to the ventilation of the eastern tropical North Atlantic (ETNA) at intermediate depth, and decadal to multidecadal changes in the strengths of these jets might play a significant role in modulating long-term oxygen changes in the ETNA OMZ (Brandt et al., 2010).

The Atlantic and Pacific OMZs have many similarities, particularly regarding OMZ shape and circulation pattern. The ETNA and the eastern tropical South Pacific (ETSP) OMZs (Figs. 1, 2) are both located in the shadow zones of the ventilated thermocline and are ventilated by lateral and vertical mixing as well as by zonal advection in the equatorial band. However, the striking difference between both OMZs is that the ETNA OMZ is hypoxic (oxygen below $\sim 60$ to $120 \mu \mathrm{mol} \mathrm{kg}{ }^{-1}$ ) and the ETSP is suboxic (oxygen below about $10 \mu \mathrm{mol} \mathrm{kg}{ }^{-1}$ ). Karstensen et al. (2008) concluded that this difference is the result of reduced oxygen levels in the eastward current bands of the Pacific OMZs compared to the Atlantic OMZs, which they argue can be traced back to the larger ratio of the total volume of the OMZ layer to the renewal or subduction rate in the Pacific compared to the Atlantic.

As part of the Collaborative Research Center 754 (Sonderforschungsbereich, SFB 754) "Climate-Biogeochemistry Interactions in the Tropical Ocean" (first phase 2008-2011 and second phase 2012-2015), physical processes responsible for the ventilation of the ETNA OMZ have been studied using an extended observational programme including repeat hydrography by shipboard and glider measurements, an array of subsurface moorings, microstructure measurements and two tracer release experiments. The goals of the research programme are to deliver an improved understanding of the ventilation physics of the ETNA OMZ, to come up with a quantitative understanding of the functioning of the OMZs, to monitor regional oxygen variability and trends, and to analyse their causes. The ETSP OMZ has been studied as well using a reduced observational programme. However, the comparison between the hypoxic ETNA and the suboxic ETSP is of particular interest here, as the observed deoxygenation in the ETNA, or future climate change, might lead to a shift from hypoxic to suboxic conditions. The present paper provides an overview of the current status of the science regarding these topics. The paper is organised as follows: in Sect. 2, data and methods used in this study are described. In Sect. 3, the current system and the OMZ structure in the ETNA are characterised. Results for the quantification of the strength of different ventilation processes, i.e. vertical mixing, lateral mixing, and advection, are presented in Sect. 4. In Sect. 5, the current knowledge of oxygen consumption estimates is presented. The OMZ structure and processes at the continental margin are presented in Sect. 6. Long-term oxygen variability with a special focus on the period of enhanced data coverage is presented in Sect. 7. The results obtained for the ETNA OMZ are then compared with results obtained for the ETSP in Sect. 8 and, finally, in Sect. 9, the results are summarised and discussed.

\section{Ocean observations}

A major focus of the observational work presented here has been on circulation, ventilation physics, and water mass distribution. In the tropical North Atlantic, observations have been concentrated on the $23^{\circ} \mathrm{W}$ section with repeat hydrography, microstructure measurements, velocity measurements (Table 1), and moored observations (Table 2). The $23^{\circ} \mathrm{W}$ section cuts through the ETNA OMZ from south of the Cape Verde archipelago to slightly south of the Equator (Fig. 1). Along the $23^{\circ} \mathrm{W}$ section, moorings with instrumentation to observe temperature, salinity, oxygen and velocity continuously were deployed at 8 and $5^{\circ} \mathrm{N}$, delivering multi-year time series. Additionally, oxygen sensors were installed at 300 and $500 \mathrm{~m}$ in depth at selected moorings $\left(23^{\circ} \mathrm{W}, 4^{\circ}\right.$ and $11.5^{\circ} \mathrm{N}$ ) of the Prediction and Research Moored Array in the Tropical Atlantic (PIRATA; Bourles et al., 2008) and at subsurface moorings at $23^{\circ} \mathrm{W}, 2^{\circ} \mathrm{N}$ and $0^{\circ}$ (Fig. 1). For the analysis of hydrographic and velocity data acquired along $23^{\circ} \mathrm{W}$, we used the measurements given in Table 1. Besides the $23^{\circ} \mathrm{W}$ section, here we shall also present data acquired along $18^{\circ} \mathrm{N}$ at the northern boundary of the ETNA OMZ (Fig. 1, Table 1). Moreover, two tracer release experiments (TREs) were carried out in the ETNA OMZ. During the first TRE, GUTRE (Guinea Upwelling Tracer Release Experiment), in April 2008, $92 \mathrm{~kg}$ of the halocarbon tracer trifluoromethyl sulfur pentafluoride $\left(\mathrm{CF}_{3} \mathrm{SF}_{5}\right)$ were released at $23^{\circ} \mathrm{W}, 8^{\circ} \mathrm{N}$ on the potential density surface, $\sigma_{\theta}=$ $26.88 \mathrm{~kg} \mathrm{~m}^{-3}$. The depth of release, of about $330 \mathrm{~m}$, corresponds to the depth of the oxycline above the deep oxygen minimum. During the following 2.5 years, three tracer surveys were carried out to measure the vertical and horizontal spreading of the tracer (Banyte et al. (2012), Table 1). During the second TRE, OSTRE (Oxygen Supply Tracer Release Experiment), in November 2012, $88.5 \mathrm{~kg}$ of the same tracer were released at $21^{\circ} \mathrm{W}, 11^{\circ} \mathrm{N}$ on the potential density surface $\sigma_{\theta}=27.03 \mathrm{~kg} \mathrm{~m}^{-3}$, corresponding to about $500 \mathrm{~m}$ in depth, which is in the core region of the ETNA OMZ.

In the ETSP OMZ, a particular focus was on the $\sim 86^{\circ} \mathrm{W}$ section (section located at $85^{\circ} 50^{\prime} \mathrm{W}$ north of $15^{\circ} \mathrm{S}$ with a westward shift to $88^{\circ} \mathrm{W}$ south of $20^{\circ} \mathrm{S}$, called the $\sim 86^{\circ} \mathrm{W}$ section in the following) with hydrographic and current measurements from $2^{\circ} \mathrm{N}$ to about $22^{\circ} \mathrm{S}$ (Fig. 2). Two recent cruises covered that section repeating measurements taken during the RV Knorr cruise in March 1993 (Table 1). Additionally, four cruises were carried out along the continental margin of Peru (Table 1) to investigate the circulation along the continental slope and shelf off Peru as well as the physical processes contributing to the redistribution of oxygen, nutrients and other solutes. 
Table 1. Research cruises to the tropical eastern Atlantic and Pacific oceans. Depending on the measurements carried out and the geographical area covered on the different cruises, up to 22 sections were used to determine the mean $23^{\circ} \mathrm{W}$ section, 7 sections for the mean $18^{\circ} \mathrm{N}$ section and 3 sections for the mean $\sim 86^{\circ} \mathrm{W}$ section.

\begin{tabular}{|c|c|c|}
\hline Vessel and cruise (date) & Main work & Region \\
\hline \multicolumn{3}{|c|}{ Tropical Atlantic, $5^{\circ} \mathrm{S}-14^{\circ} \mathrm{N} / \sim 23^{\circ} \mathrm{W}$ and $\mathrm{OMZ}$ area } \\
\hline Thalassa (Jul-Aug 1999) & $23^{\circ} \mathrm{W}$ section & $5^{\circ} \mathrm{S}-6^{\circ} \mathrm{N}$ \\
\hline Seaward Johnson (Jan 2000) & $23^{\circ} \mathrm{W}$ section & $5^{\circ} \mathrm{S}-4^{\circ} \mathrm{N}$ \\
\hline Meteor 47/1 (Apr 2000) & $23^{\circ} \mathrm{W}$ section & $5^{\circ} \mathrm{S}-4^{\circ} \mathrm{N}$ \\
\hline Meteor 55 (Oct 2002) & $24^{\circ} \mathrm{W}$ section & $0-10^{\circ} \mathrm{N}$ \\
\hline Polarstern Ant XXII/5 (Jun 2005) & $23^{\circ} \mathrm{W}$ section & $5^{\circ} \mathrm{S}-14^{\circ} \mathrm{N}$ \\
\hline Meteor 68/1 (May 2006) & $23^{\circ} \mathrm{W}$ section & $2^{\circ} \mathrm{S}-0.5^{\circ} \mathrm{N}$ \\
\hline Ron Brown (Jun 2006) & $23^{\circ} \mathrm{W}$ section & $5^{\circ} \mathrm{S}-14^{\circ} \mathrm{N}$ \\
\hline Meteor 68/2 (Jun-Jul 2006) & $23^{\circ} \mathrm{W}$ section, moorings & $4^{\circ} \mathrm{S}-14^{\circ} \mathrm{N}$ \\
\hline Ron Brown (May 2007) & $23^{\circ} \mathrm{W}$ section & $4^{\circ} \mathrm{N}-14^{\circ} \mathrm{N}$ \\
\hline L'Atalante GEOMAR 4 (Feb-Mar 2008) & $23^{\circ} \mathrm{W}$ section, moorings & $2^{\circ} \mathrm{S}-14^{\circ} \mathrm{N}$ \\
\hline Maria S. Merian 08/1 (Apr-May 2008) & $23^{\circ} \mathrm{W}$ section, GUTRE tracer release & $7.5-14^{\circ} \mathrm{N}, 23^{\circ} \mathrm{W}, 8^{\circ} \mathrm{N}$ at $330 \mathrm{~m}$ \\
\hline Maria S. Merian 10/1 (Nov-Dec 2008) & GUTRE tracer survey & $4-14^{\circ} \mathrm{N} / 27.5-17.5^{\circ} \mathrm{W}$ \\
\hline Polarstern Ant XXV/5 (May 2009) & $23^{\circ} \mathrm{W}$ section & $5^{\circ} \mathrm{S}-14^{\circ} \mathrm{N}$ \\
\hline Endeavor 463 (May-Jun 2009) & $23^{\circ} \mathrm{W}$ section & $5^{\circ} \mathrm{S}-3^{\circ} \mathrm{N}$ \\
\hline Ron Brown (Jul-Aug 2009) & $23^{\circ} \mathrm{W}$ section & $0-14^{\circ} \mathrm{N}$ \\
\hline Meteor 80/1 (Oct-Nov 2009) & $23^{\circ} \mathrm{W}$ section, moorings & $5^{\circ} \mathrm{S}-14^{\circ} \mathrm{N}$ \\
\hline Polarstern Ant XXVI/1 (Nov 2009) & $23^{\circ} \mathrm{W}$ section & $5^{\circ} \mathrm{S}-14^{\circ} \mathrm{N}$ \\
\hline Meteor 80/2 (Dec 2009) & GUTRE tracer survey & $4-14^{\circ} \mathrm{N} / 31-15^{\circ} \mathrm{W}$ \\
\hline Meteor 81/1 (Feb-Mar 2010) & $22^{\circ} \mathrm{W}$ section & $5^{\circ} \mathrm{S}-13^{\circ} \mathrm{N}$ \\
\hline Polarstern Ant XXVI/4 (May 2010) & $23^{\circ} \mathrm{W}$ section & $5^{\circ} \mathrm{S}-13.5^{\circ} \mathrm{N}$ \\
\hline Meteor 83/1 (Oct-Nov 2010) & GUTRE tracer survey & $2-15^{\circ} \mathrm{N} / 28-15^{\circ} \mathrm{W}$ \\
\hline Maria S. Merian 18/2 (May-Jun 2011) & $23^{\circ} \mathrm{W}$ section, moorings & $5^{\circ} \mathrm{S}-14^{\circ} \mathrm{N}$ \\
\hline Maria S. Merian 18/3 (Jun-Jul 2011) & $23^{\circ} \mathrm{W}$ section & $4-14^{\circ} \mathrm{N}$ \\
\hline Ron Brown (Jul-Aug 2011) & $23^{\circ} \mathrm{W}$ section & $0-14^{\circ} \mathrm{N}$ \\
\hline Maria S. Merian 22 (Oct-Nov 2012) & $23^{\circ} \mathrm{W}$ section, moorings & $5^{\circ} \mathrm{S}-14^{\circ} \mathrm{N}$ \\
\hline Maria S. Merian 23 (Dec 2012) & $23^{\circ} \mathrm{W}$ section, OSTRE tracer release & $4^{\circ} \mathrm{S}-5^{\circ} \mathrm{N}, 21^{\circ} \mathrm{W}, 11^{\circ} \mathrm{N}$ at $500 \mathrm{~m}$ \\
\hline Meteor 97 (May-Jun 2013) & OSTRE tracer survey & $8-12^{\circ} \mathrm{N} / 23-19^{\circ} \mathrm{W}$ \\
\hline Meteor 106 (Apr-May 2014) & $23^{\circ} \mathrm{W}$ section, moorings & $5^{\circ} \mathrm{S}-14^{\circ} \mathrm{N}$ \\
\hline \multicolumn{3}{|c|}{ Tropical Atlantic, $26-16^{\circ} \mathrm{W} / 18^{\circ} \mathrm{N}$} \\
\hline P320/1 (Mar-Apr 2005) & $18^{\circ} \mathrm{N}$ section & $19-16.4^{\circ} \mathrm{W}$ \\
\hline Meteor M68/3 (Jul-Aug 2006) & $18^{\circ} \mathrm{N}$ section & $26-16.3^{\circ} \mathrm{W}$ \\
\hline P347 (Jan-Feb 2007) & $18^{\circ} \mathrm{N}$ section & $17.5-16.3^{\circ} \mathrm{W}$ \\
\hline P348 (Mar 2007) & $18^{\circ} \mathrm{N}$ section & $23.2-16.4^{\circ} \mathrm{W}$ \\
\hline L'Atalante GEOMAR 3 (Feb 2008) & $18^{\circ} \mathrm{N}$ section & $24.3-16.3^{\circ} \mathrm{W}$ \\
\hline P399/2 (Jun 2010) & $18^{\circ} \mathrm{N}$ section & $21-16.5^{\circ} \mathrm{W}$ \\
\hline Maria S. Merian 22 (Nov 2012) & $18^{\circ} \mathrm{N}$ section & $26-20^{\circ} \mathrm{W}$ \\
\hline
\end{tabular}

Tropical Pacific, $22^{\circ} \mathrm{S}-2^{\circ} \mathrm{N} / \sim 86^{\circ} \mathrm{W}$ and continental slope

\begin{tabular}{lll}
\hline Knorr (Mar-Apr 1993) & $\sim 86^{\circ} \mathrm{W}$ section & $22^{\circ} \mathrm{S}-2^{\circ} \mathrm{N}$ \\
Meteor 77/3 (Jan 2009) & Continental slope & $18-10^{\circ} \mathrm{S}$ \\
Meteor 77/4 (Feb 2009) & $\sim 86^{\circ} \mathrm{W}$ section & $14^{\circ} \mathrm{S}-2^{\circ} \mathrm{N}$ \\
Meteor 90 (Nov 2012) & $\sim 86^{\circ} \mathrm{W}$ section & $22^{\circ} \mathrm{S}-2^{\circ} \mathrm{N}$ \\
Meteor 91 (Dec 2012) & Continental slope & $17-5^{\circ} \mathrm{S}$ \\
Meteor 92 (Jan 2013) & Continental slope & $13-10^{\circ} \mathrm{S}$ \\
Meteor 93 (Feb 2013) & Continental slope & $14-10^{\circ} \mathrm{S}$ \\
\hline
\end{tabular}


Table 2. Moored oxygen observations in the eastern tropical Atlantic along $23^{\circ} \mathrm{W}$.

\begin{tabular}{llll}
\hline Position & Period & Mooring type & Depth (m) \\
& & & \\
\hline $0^{\circ} / 23^{\circ} \mathrm{W}$ & Mar 2008-Oct 2012 & Subsurface & 300,500 \\
$2^{\circ} \mathrm{N} / 23^{\circ} \mathrm{W}$ & Feb 2008-May 2011 & Subsurface & 300,500 \\
$4^{\circ} \mathrm{N} / 23^{\circ} \mathrm{W}$ & Jul 2009-Jan 2013 & PIRATA & 300,500 \\
$5^{\circ} \mathrm{N} / 23^{\circ} \mathrm{W}$ & Nov 2009-Oct 2012 & Subsurface & $100-800$ \\
$8^{\circ} \mathrm{N} / 23^{\circ} \mathrm{W}$ & Nov 2009-Oct 2012 & Subsurface & $100-800$ \\
$11.5^{\circ} \mathrm{N} / 23^{\circ} \mathrm{W}$ & Jul 2009-Jan 2013 & PIRATA & 300,500 \\
\hline
\end{tabular}

\section{Structure of the ETNA OMZ}

The subtropical gyre circulation of the Northern Hemisphere is, to first order, determined by the negative wind stress curl associated with mid-latitude westerlies and northeasterly trade winds. The resulting Ekman pumping drives subduction of oxygen-rich surface water masses in the subtropics. According to theory, equatorward and westward propagation of subducted water masses forms the northern boundary of the shadow zone of the ventilated thermocline (Luyten et al., 1983b). Within the shadow zone, which is characterised by a weak mean circulation, the ETNA OMZ with a core depth at about $400 \mathrm{~m}$ is found. Lowest oxygen concentrations at the core depth are found away from the continental margin at about $20^{\circ} \mathrm{W}, 10^{\circ} \mathrm{N}$ (Fig. 3). North of the ETNA OMZ, the North Equatorial Current (NEC) flows southwestward along the Cape Verde Frontal Zone. It transports oxygen-rich Central Water $(\mathrm{CW})$ formed by subduction in the subtropics as well as intermediate water masses in the deeper layers that have their origin mainly in the Labrador Sea and the Mediterranean outflow. To the south, the ETNA OMZ is bounded by the energetic zonal flows near the Equator forming the equatorial oxygen maximum (Brandt et al., 2012). Above the main deep OMZ, at a depth of about $100 \mathrm{~m}$, a shallow OMZ is situated, defined as the secondary oxygen minimum below the surface mixed layer and above $200 \mathrm{~m}$ (Fig. 4). It is characterised by generally higher oxygen levels compared to the deep OMZ, while occasionally, extremely low oxygen levels are possible, and are most pronounced in the northeastern part of the shadow zone close to the highly productive eastern boundary upwelling region off Mauritania and Senegal (Fischer et al., 2013). The mean $18^{\circ} \mathrm{N}$ section shows shallow mixed-layer depths over the continental margin typical of coastal upwelling regions as well as lower salinities in the $\mathrm{CW}$ layer that are a consequence of the northward transport of Southern Hemisphere water along the continental slope within the Poleward Undercurrent (Barton, 1989) and the surface flow associated with the Mauritania Current (Mittelstaedt, 1983) (Fig. 5).

The western boundary of the Atlantic Ocean is associated with relatively high oxygen levels at all latitudes (Fig. 1). At the density of the OMZ layer, the North Brazil Undercurrent

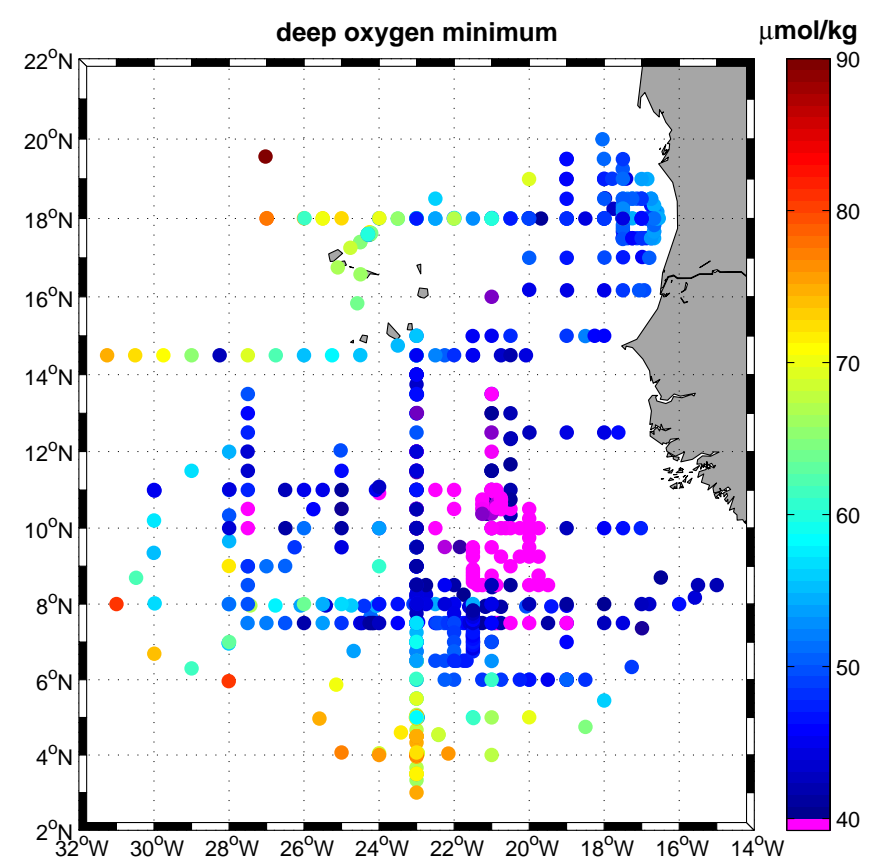

Figure 3. Minimum oxygen concentration below $200 \mathrm{~m}$ (representing the deep oxygen minimum) as obtained from CTD station data taken during the period 2006-2013. Oxygen concentration at the deep oxygen minimum below $40 \mu \mathrm{mol} \mathrm{kg}{ }^{-1}$ is marked by purple dots.

(NBUC)/North Brazil Current (NBC) (Schott et al., 2005) transports central and intermediate water masses of Southern Hemisphere origin northward. The high oxygen concentrations in the CW layer of the NBUC can be traced back along the southern branches of the South Equatorial Current (SEC) to the subduction region in the eastern subtropical gyre (Tsuchiya, 1986; Stramma and England, 1999). The CW also includes water from the Indian Ocean that is brought into the Atlantic by eddy shedding from the Agulhas retroflection.

The Antarctic Intermediate Water (AAIW) below the CW originates mainly from the Drake Passage and is transported around the Southern Hemisphere subtropical gyre to feed into the NBUC (Suga and Talley, 1995). Of importance for the ventilation of the ETNA OMZ is the northward flow of $\mathrm{CW}$ and AAIW across the Equator. The northward penetration of Southern Hemisphere water masses at the western boundary changes with depth: AAIW dominates as far as $15^{\circ} \mathrm{N}$, and the upper $\mathrm{CW}$ only as far as $10^{\circ} \mathrm{N}$, because of the presence of water masses of Northern Hemisphere origin (Kirchner et al., 2009).

A substantial part of the water masses transported northward within the NBUC forms the upper branch of the Atlantic Meridional Overturning Circulation (AMOC), a circulation known since the German Meteor cruises in the 1920s, as documented by Wüst (1935). The presence of the AMOC under present climate conditions is identified as the main 


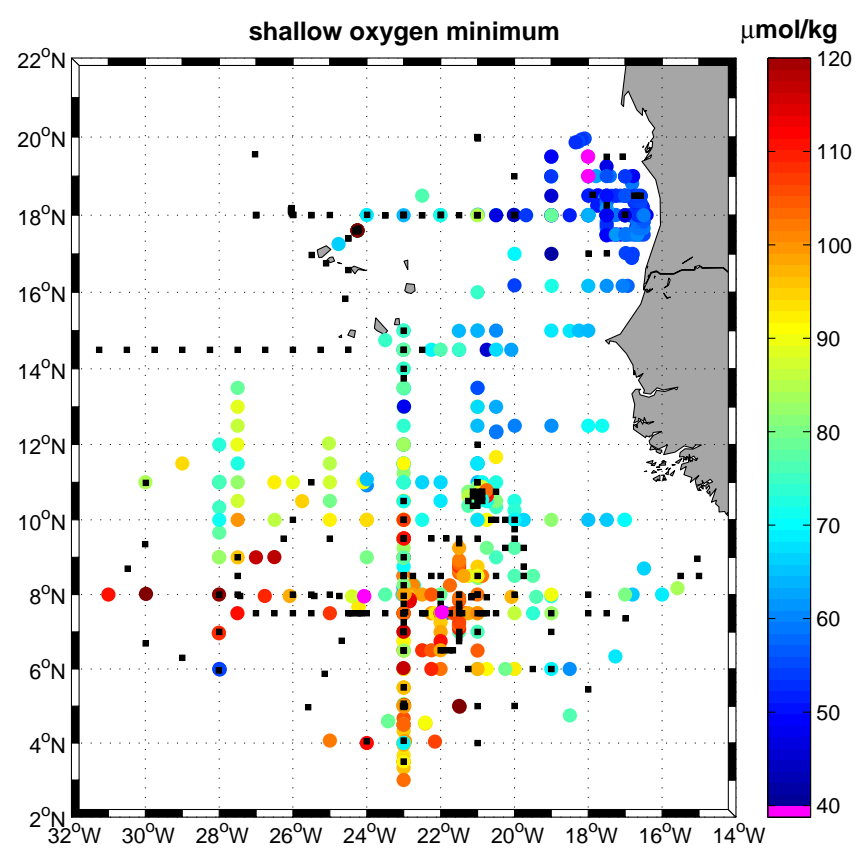

Figure 4. Minimum oxygen concentration above $200 \mathrm{~m}$ (representing the shallow oxygen minimum) as obtained from CTD station data taken during the period 2006-2013. Black squares indicate profiles without a shallow oxygen minimum (i.e. the minimum oxygen concentration was found at the lower boundary of the chosen depth range, that is $200 \mathrm{~m}$ ). Oxygen concentration at the shallow oxygen minimum below $40 \mu \mathrm{mol} \mathrm{kg}^{-1}$ is marked by purple dots.

reason for the dominance of Southern Hemisphere water masses in the tropical North Atlantic discussed above. It contributes to the asymmetric shallow overturning circulations in both hemispheres as well, the subtropical cell (STC) of the Northern Hemisphere being much weaker than its counterpart in the Southern Hemisphere (Schott et al., 2004). The STC connects the subduction regions of the eastern subtropical gyres to the equatorial and coastal upwelling regions. In the Northern Hemisphere, the subducted water masses mostly do not reach the Equator. Instead, they contribute to the eastward flow within the North Equatorial Counter Current (NECC)/North Equatorial Undercurrent (NEUC) at about $5^{\circ} \mathrm{N}$ (Zhang et al., 2003). A particular feature in the ETNA is the presence of an open ocean upwelling regime within the cyclonic circulation of the Guinea Dome south of the Cape Verde archipelago. Associated with the presence of the Guinea Dome are changes in the potential vorticity distribution that further limit the flow of newly subducted water masses from the Northern Hemisphere subtropics toward the Equator within the STC (Malanotte-Rizzoli et al., 2000).

The $23^{\circ} \mathrm{W}$ section (Fig. 6) cuts through the ETNA OMZ, which can be identified by low oxygen levels as well as by the high age of the water masses. The gradual change in salinity on density surfaces along this section defines the transition between low- and high-saline water masses of southern and
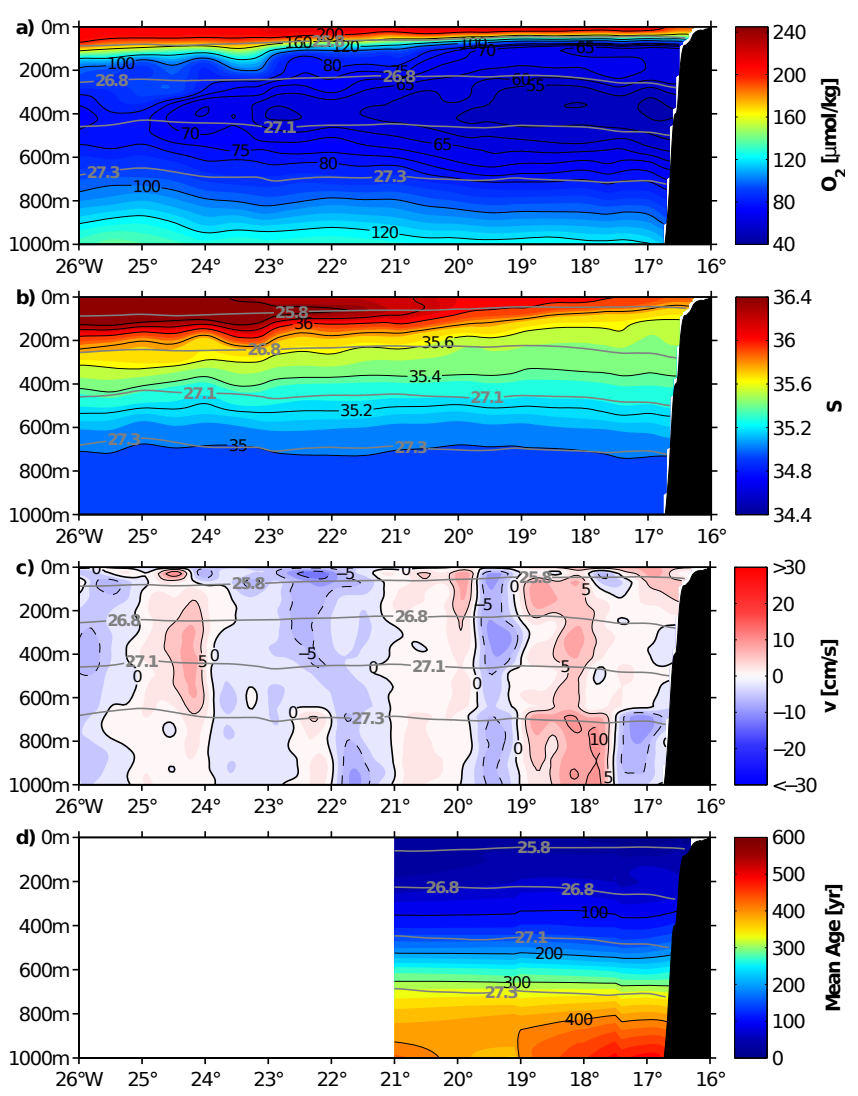

Figure 5. (a) Mean oxygen content, (b) salinity, (c) meridional velocity (positive northward), and (d) mean age as obtained from zonal ship sections taken along $18^{\circ} \mathrm{N}$ from 2005 to 2012. Grey contours mark potential density $\left(\mathrm{kg} \mathrm{m}^{-3}\right)$. Besides the deep oxygen minimum at about $400 \mathrm{~m}$ in depth, there is a shallow oxygen minimum at about $100 \mathrm{~m}$ in proximity to the shelf (a).

northern origin, respectively. Along this section, mean eastward and westward flow is typically identified by positive and negative oxygen anomalies relative to the background oxygen distribution (Brandt et al., 2010).

Ventilation timescales of the interior ocean can be quantified by analysing transient tracer distributions. A comprehensive set of CFC-12 and $\mathrm{SF}_{6}$ measurements in the ETNA (these tracers were measured in parallel to the deliberately released $\mathrm{CF}_{3} \mathrm{SF}_{5}$ tracer) has been explored in detail by Schneider et al. (2012) using the concept of transit time distributions (TTDs) (e.g. Waugh et al., 2004). The mean age in the centre of the OMZ $\left(\sigma_{\theta}=27.0 \mathrm{~kg} \mathrm{~m}^{-3}\right)$ is in the range of 120 to 180 years (Fig. 7). The mean age refers to the average time it takes for a water parcel to reach a certain location in the interior ocean from the time it was last in contact with the surface ocean and hence the atmosphere (see Sect. 5 for more discussion on the TTD concept). In contrast to waters in the $\mathrm{OMZ}$ centre, water south of about $5^{\circ} \mathrm{N}$ is significantly better ventilated, with mean ages close to 100 years, reflecting the more energetic circulation in the equatorial region. Roughly 

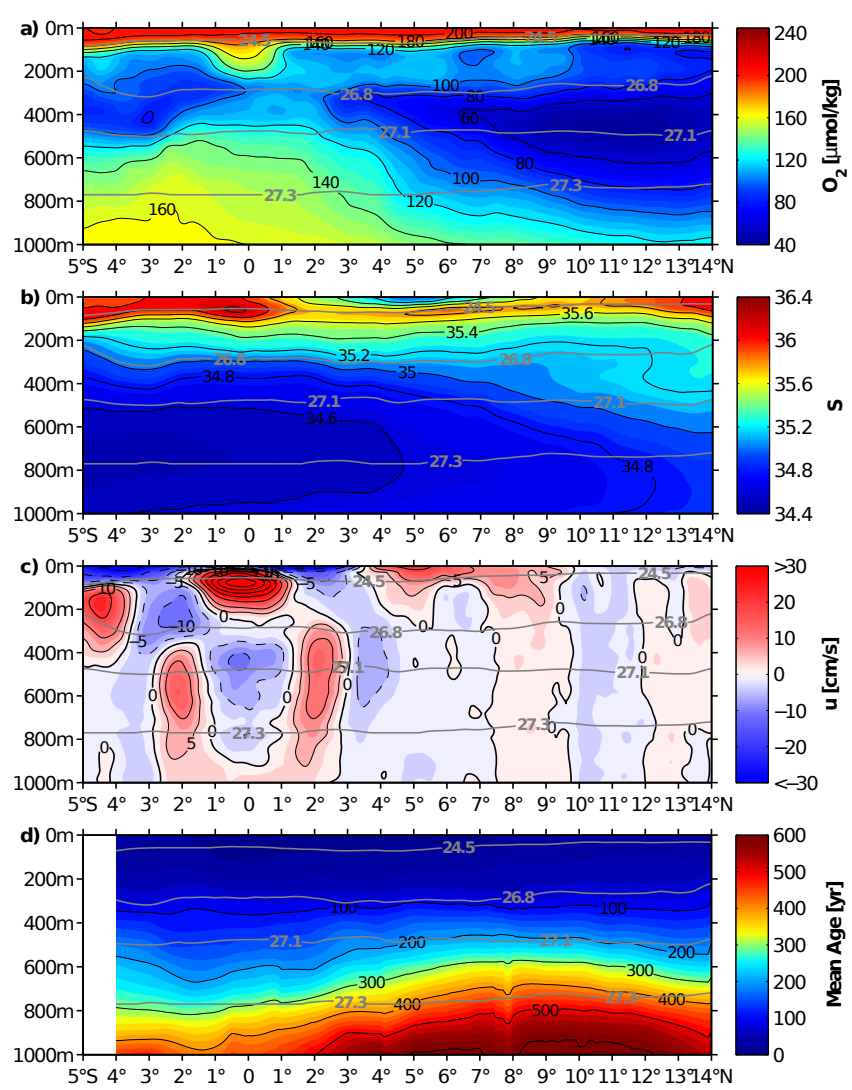

Figure 6. (a) Mean oxygen content, (b) salinity, (c) zonal velocity (positive eastward), and (d) mean age as obtained from meridional ship sections taken along $23^{\circ} \mathrm{W}$ during 1999-2012. Grey contours mark potential density $\left(\mathrm{kg} \mathrm{m}^{-3}\right)$. Eastward current bands, marked by reddish colours, are generally associated with elevated oxygen content.

the same age is found north of about $13^{\circ} \mathrm{N}$ close to the Cape Verde Islands despite lower oxygen values in the northern region compared to the southern region. Below the poorly ventilated OMZ, the even older AAIW $\left(\sigma_{\theta}=27.3 \mathrm{~kg} \mathrm{~m}^{-3}\right)$ with ventilation times in excess of 500 years is found (close to the detection limit of the CFCs, and thus difficult to quantify accurately), although this water mass has a high oxygen concentration. Again, at this density layer, the area south of $5^{\circ} \mathrm{N}$ is significantly better ventilated than north of $5^{\circ} \mathrm{N}$ (Schneider et al., 2012).

\section{Ventilation processes}

The oxygen budget of the OMZ takes account of consumption, advection, and diffusion of oxygen. Any imbalance of these terms results in decreasing or increasing oxygen concentrations. While consumption is an oxygen sink, advection and diffusion might be sources or sinks, depending on the background conditions. Mean advection of oxygen manifests itself in the mean oxygen and velocity distributions: along

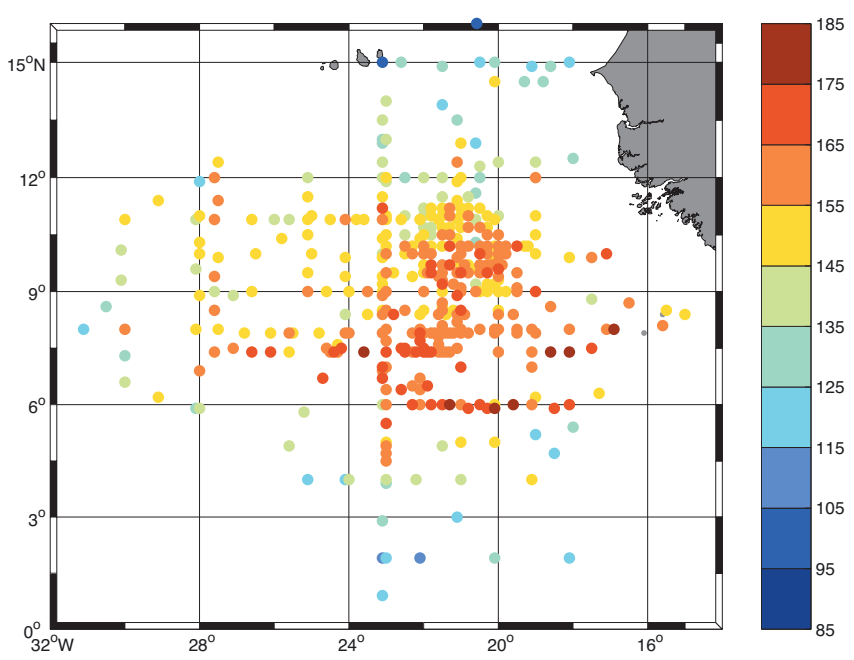

Figure 7. Mean age (yr) at $\sigma_{\theta}=27.0 \mathrm{~kg} \mathrm{~m}^{-3}$, which corresponds approximately to the depth of the deep oxygen minimum.

$23^{\circ} \mathrm{W}$, mean eastward current bands are generally associated with an elevated oxygen content (Fig. 6) representing an advective ventilation pathway from the western boundary toward the OMZ (Brandt et al., 2010). Horizontal and vertical diffusion act on the mean horizontal and vertical oxygen gradients, respectively. The associated variance production by mesoscale eddy stirring and small-scale turbulence (Ferrari and Polzin, 2005) results in locally elevated oxygen variance. The Eulerian variance along $23^{\circ} \mathrm{W}$, as obtained from ship sections, might additionally result from lateral meandering of zonal currents or from vertical movements of isopycnals associated with internal waves and eddies. Moored time series reflect this variability pattern. There is generally higher oxygen variance at $300 \mathrm{~m}$ in depth close to the oxycline above the deep OMZ core compared to at $500 \mathrm{~m}$ in depth (cf. Figs. 8, 9). Timescales of processes driving the variance in moored time series cover a wide range from those associated with internal waves and tides, inertial oscillations, and the mesoscale eddy field to seasonal and interannual variability, including planetary waves (Hahn et al., 2014). Using repeat ship sections, the effect of vertical motion of isopycnals can be removed by calculating oxygen variance on potential density surfaces and projecting back onto depth space (Fig. 10). The remaining oxygen variance in regions of weak mean flow surrounding the ETNA OMZ might be associated with processes responsible for the vertical and lateral mixing that is discussed in the following subsections.

\subsection{Vertical mixing}

Vertical mixing acts on the vertical oxygen gradients and leads to an oxygen supply to the OMZ via down-gradient oxygen fluxes. In order to estimate the vertical or diapycnal oxygen supply, the diapycnal diffusivity $K_{\rho}$ as a measure for diapycnal mixing is required. From the diapycnal spread of 

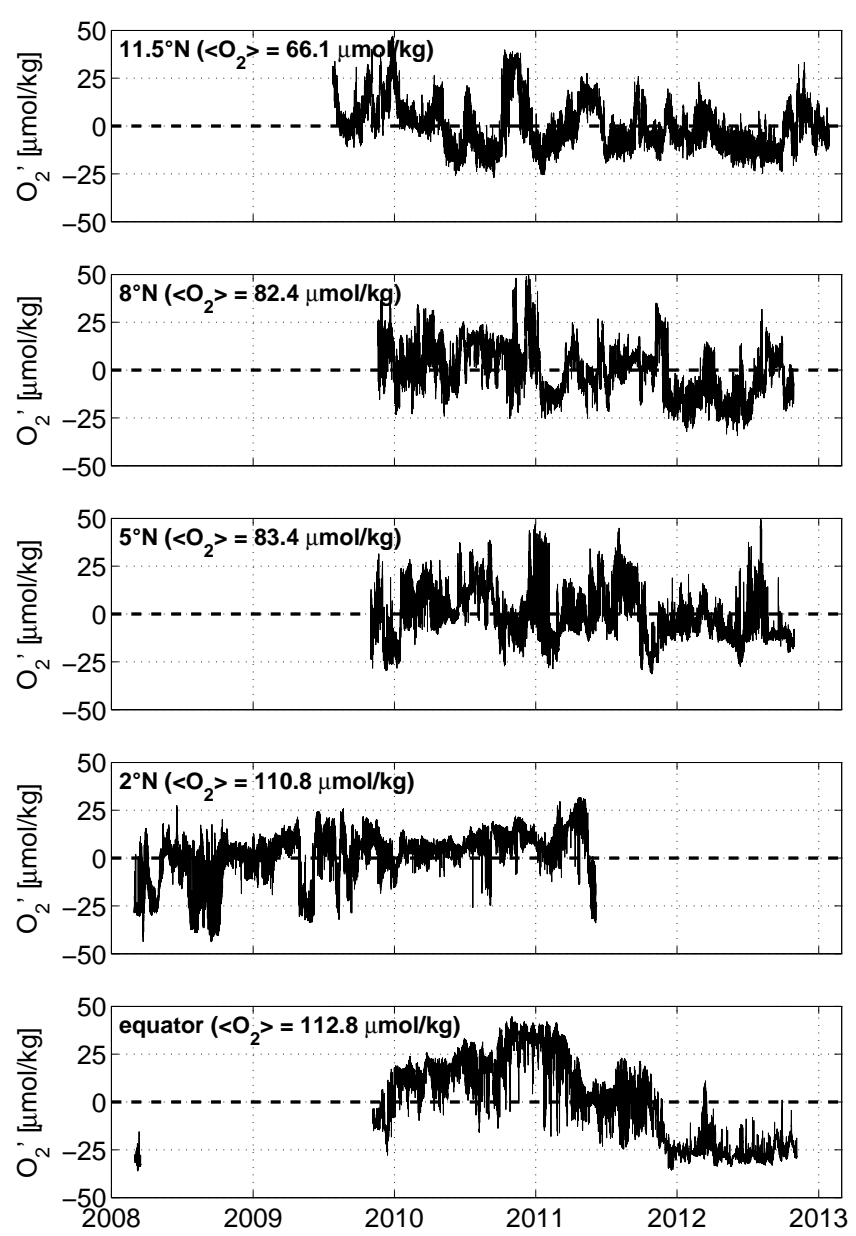

Figure 8. Time series of the oxygen anomaly at about $300 \mathrm{~m}$ in depth from moored observations along $23^{\circ} \mathrm{W}$ at different latitudes. Mean oxygen values at the different mooring locations are given in brackets.

the deliberately released tracer during GUTRE, a mean diapycnal diffusivity of $(1.2 \pm 0.2) \times 10^{-5} \mathrm{~m}^{2} \mathrm{~s}^{-1}$ was derived (Banyte et al., 2012). The tracer was injected on the isopycnal $\sigma_{\theta}=26.88 \mathrm{~kg} \mathrm{~m}^{-3}$ (about $330 \mathrm{~m}$ ), corresponding to the oxycline above the deep OMZ. GUTRE was accompanied by extensive microstructure and finescale shear measurements that delivered an estimate of $(1.0 \pm 0.2) \times 10^{-5} \mathrm{~m}^{2} \mathrm{~s}^{-1}$ for $K_{\rho}$ for the depth range between 150 and $500 \mathrm{~m}$ (Fischer et al., 2013). The value inferred from microstructure measurements only considers diapycnal mixing due to small-scale turbulence. However, double diffusive enhancement was found to be small $\left(\sim 0.1 \times 10^{-5} \mathrm{~m}^{2} \mathrm{~s}^{-1}\right)$ in this depth interval (Fischer et al., 2013), so the total diffusivities estimated by the two independent methods agree within the error bars. This estimate of diapycnal mixing is considerably larger than the expected background mixing at this latitude (e.g. Gregg et al., 2003), probably due to the presence of rough topography (e.g. the Sierra Leone Rise) in the southern part of the OMZ. Combining $K_{\rho}$ with simultaneous profiles of the vertical oxygen
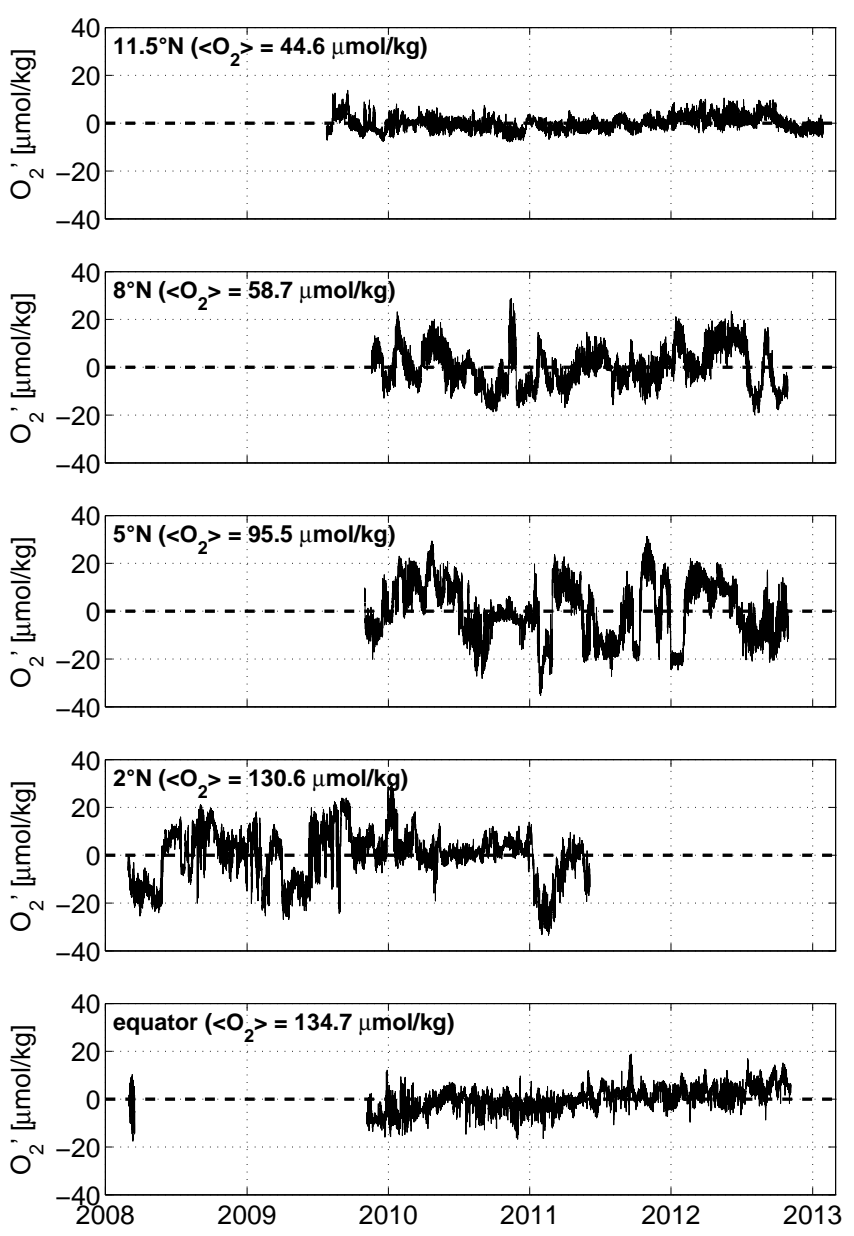

Figure 9. As Fig. 8, but at about $500 \mathrm{~m}$ in depth.

gradient allows determination of the profile of the diapycnal oxygen flux. Its divergence represents the oxygen supply to the OMZ and amounted to about $1 \mu \mathrm{mol} \mathrm{kg}-1 \mathrm{yr}^{-1}$ in the $\mathrm{OMZ}$ core, with the required oxygen transported downwards from the upper CW (Fischer et al., 2013).

Deeper-ranging microstructure profiles acquired during the most recent cruises to the ETNA OMZ (Table 1) allowed us to extend the analysis into the deeper water column down to $800 \mathrm{~m}$ in depth, i.e. allowed us to estimate the diapycnal oxygen flux from the AAIW below as well. In total, 200 microstructure profiles, 40 of them down to $800 \mathrm{~m}$, were about equally partitioned into three subregions of the OMZ: a seamount subregion ( $7 \%$ of OMZ area), an abyssal plain subregion ( $80 \%$ of OMZ area), and a transition subregion (13\% of OMZ area). They served to estimate subregional mean profiles of the turbulent part of diapycnal diffusivity (Fig. 11). Double diffusive enhancement of $K_{\rho}$ from simultaneous CTD profiles for each subregion following St. Laurent and Schmitt (1999) was accounted for to obtain subregional total $K_{\rho}$ profiles (Fig. 11) and an area-weighted mean total $K_{\rho}$ profile (Fig. 12). The mean diapycnal supply (Fig. 13) that, in the following, will be used in the oxygen budget, was 


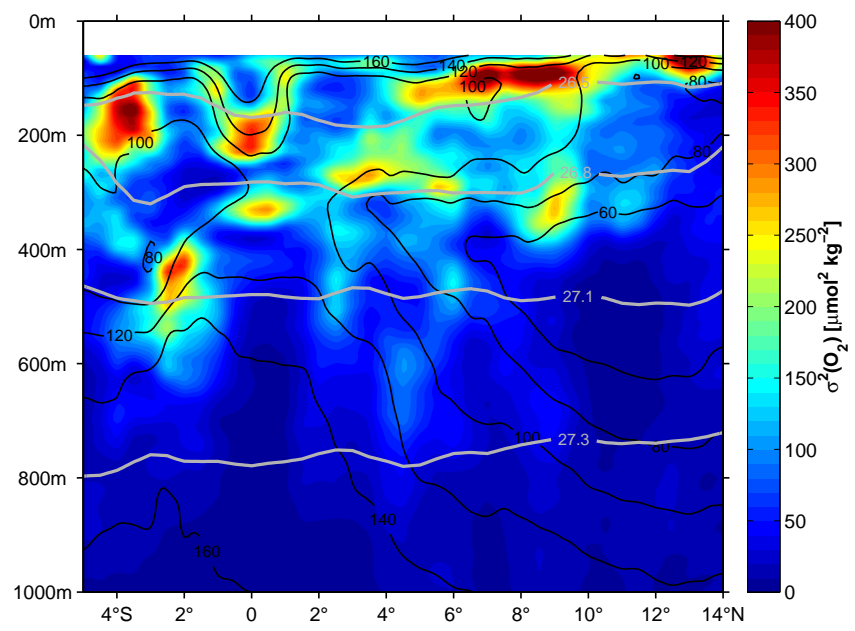

Figure 10. Oxygen variance along $23^{\circ} \mathrm{W}$ from repeat ship sections. The analysis was done on isopycnal surfaces and the results were projected back onto depth coordinates. Grey contours mark potential density $\left(\mathrm{kg} \mathrm{m}^{-3}\right)$; black contours mark mean oxygen $\left(\mu \mathrm{mol} \mathrm{kg} \mathrm{kg}^{-1}\right)$.

then derived as the divergence of the low-pass filtered mean diapycnal flux. The mean flux profile was calculated as the area-weighted mean of the three flux profiles from the three subregions, which in turn were obtained by combining mean $K_{\rho}$ with vertical oxygen gradient profiles from the three subregions. Error estimates are reported as $95 \%$ confidence limits and are based on standard errors of the mean of individual $K_{\rho}$ and oxygen gradient profiles for each subregion. Subsequent error estimates for the mean total $K_{\rho}$ profile (Fig. 12), flux profiles, and the mean supply profile (Fig. 13) were obtained from Gaussian error propagation (Ferrari and Polzin, 2005; Schafstall et al., 2010).

\subsection{Lateral mixing}

Lateral mixing is induced to first order by oceanic mesoscale activity, which predominantly acts along isopycnal surfaces. It effectively mixes oxygen in regions with strong isopycnal oxygen gradients, thus substantially contributing to the ventilation of an OMZ across its lateral boundaries (Luyten et al., 1983a; McCreary et al., 2013; Gnanadesikan et al., 2013; Hahn et al., 2014). For the ETNA OMZ, the eddy-driven meridional oxygen flux could be quantified along $23^{\circ} \mathrm{W}$, both by a diffusive flux parameterisation and by eddy correlation (Hahn et al., 2014).

The diffusive flux parameterisation as the first method rests on the idea that the eddy-driven along-isopycnal oxygen flux can be expressed as a diffusive flux $F^{\mathrm{d}}=K_{\mathrm{e}} \nabla \mathrm{O}_{2}$ which is down the mean oxygen gradient $\nabla \mathrm{O}_{2}$ with a horizontal eddy diffusivity $K_{\mathrm{e}}$. Two independent estimates of the meridional component of $K_{\mathrm{e}}$ for the ETNA regime were derived. On the one hand, Banyte et al. (2013) analysed the lateral spreading of the tracer released at $330 \mathrm{~m}$ during GUTRE.

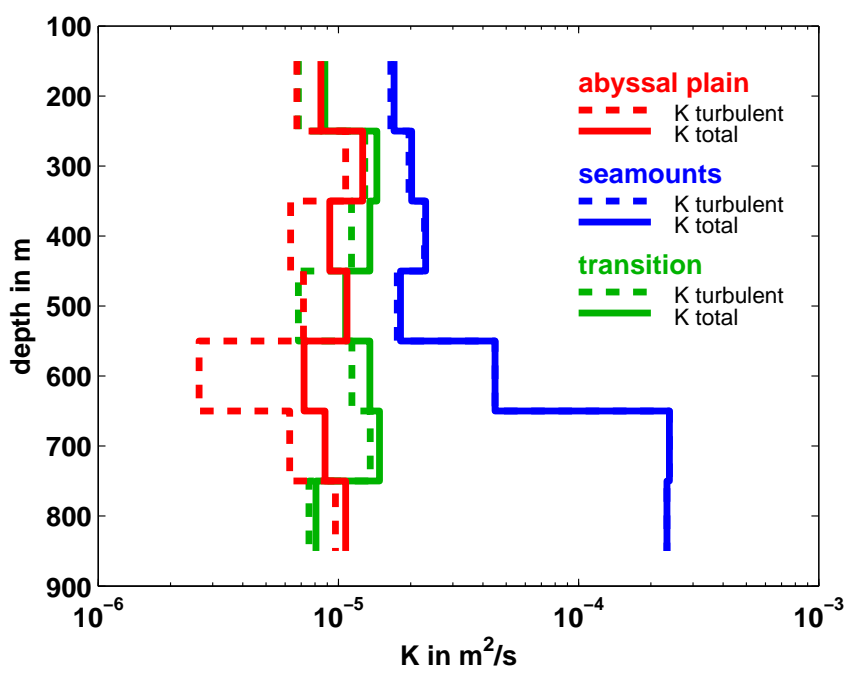

Figure 11. Profiles of the diapycnal eddy diffusivity as estimated from microstructure measurements (dashed lines) and by accounting for the effect of double diffusion (solid lines) for different regions: (red) abyssal plain, (blue) seamount region, and (green) transition region.

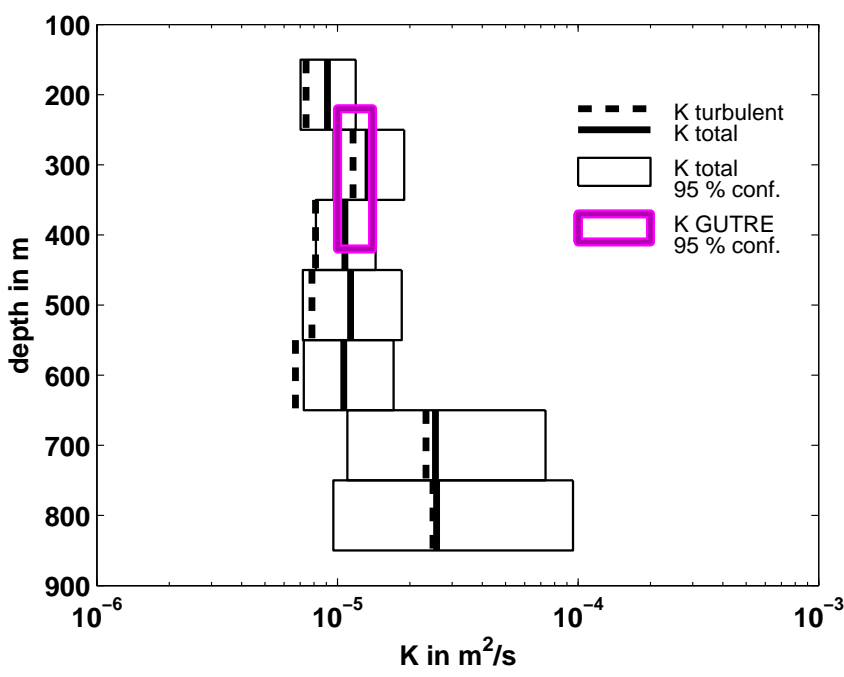

Figure 12. Profiles of diapycnal eddy diffusivity as estimated from microstructure measurements (dashed black line) and total diapycnal diffusivity after accounting for the effect of double diffusion (solid black line with $95 \%$ confidence error level). The purple box represents the $95 \%$ confidence error level of total diapycnal diffusity as estimated from the tracer release experiment.

On the other hand, Hahn et al. (2014) used hydrographic and velocity observations in the upper $1000 \mathrm{~m}$ from research vessels and moorings along $23^{\circ} \mathrm{W}$ during the last 15 years. Fundamentally, Hahn et al. (2014) based their analysis on the mixing length theory (as applied in Ferrari and Polzin, 2005) as well as on the theory of two-dimensional mesoscale turbulence on a $\beta$ plane (Eden, 2007). 


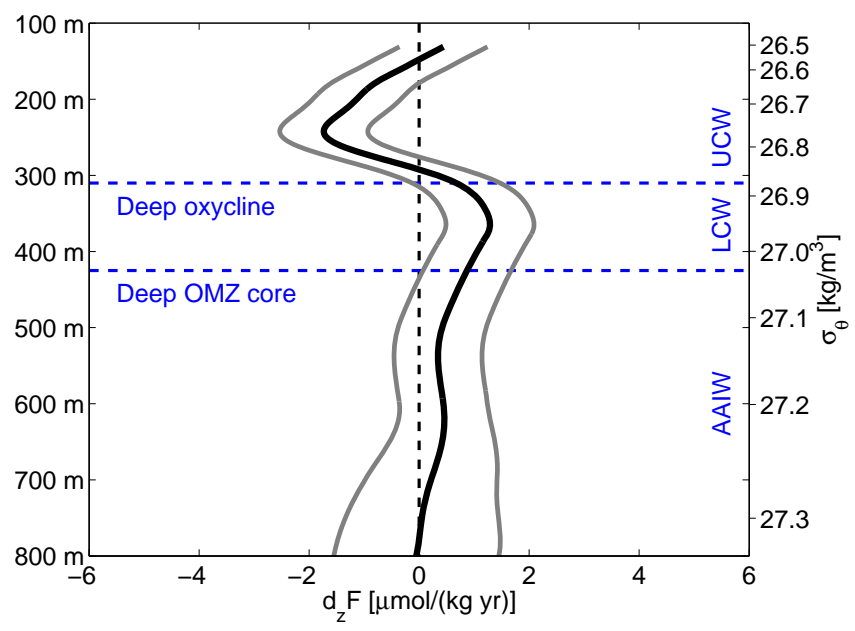

Figure 13. Mean oxygen supply due to diapycnal mixing (solid black line) for the open ocean ETNA OMZ and $95 \%$ confidence error level (solid grey lines) as function of depth (left axis) or potential density (right axis). Blue dashed lines mark the depths of the deep oxycline and of the core of the deep OMZ that separate layers of upper and lower CW, and AAIW.

By comparing observed and simulated tracer distributions, Banyte et al. (2013) estimated a meridional eddy diffusivity of $500 \mathrm{~m}^{2} \mathrm{~s}^{-1}$ at about $300 \mathrm{~m}$ with an uncertainty of $200 \mathrm{~m}^{2} \mathrm{~s}^{-1}$ (Fig. 14). Hahn et al. (2014) estimated a meridional eddy diffusivity profile for the upper $1000 \mathrm{~m}$ with the range of uncertainty assumed as large as a factor of 2 following Ferrari and Polzin (2005). The profile shows maximum eddy diffusivity close to the surface and decreasing values with depth (Fig. 14). At $300 \mathrm{~m}$, it yields $580 \mathrm{~m}^{2} \mathrm{~s}^{-1}$, which is in good agreement with the estimate from Banyte et al. (2013). Together with the mean oxygen distribution, the obtained meridional eddy diffusivity was applied to derive the eddy-driven meridional oxygen flux along $23^{\circ} \mathrm{W}$.

As a second method, the eddy correlation was used to calculate the eddy-driven meridional oxygen flux along isopycnal surfaces directly using mooring time series of oxygen and meridional velocity acquired at $5^{\circ} \mathrm{N}, 23^{\circ} \mathrm{W}$ and $8^{\circ} \mathrm{N}$, $23^{\circ} \mathrm{W}$ in the years $2009-2012$ and 2011-2012, respectively (see Hahn et al. (2014) for details). Although both estimation methods are accompanied by large uncertainties, a comparison of the results at the mooring sites reveals coherent profiles of the meridional oxygen flux (100-800 m). At the depth of the OMZ, they yield a northward oxygen flux towards the centre of the OMZ.

The oxygen that is meridionally supplied to the ETNA OMZ regime by lateral mixing can then be derived as the divergence of the eddy-driven meridional oxygen flux. The average profile of this eddy-driven meridional oxygen supply $\left(6-14^{\circ} \mathrm{N}, 23^{\circ} \mathrm{W}\right)$ obtained using the diffusive flux parameterisation shows a substantial gain of oxygen at the depth of the OMZ and a loss of oxygen above (Fig. 14). The corre-

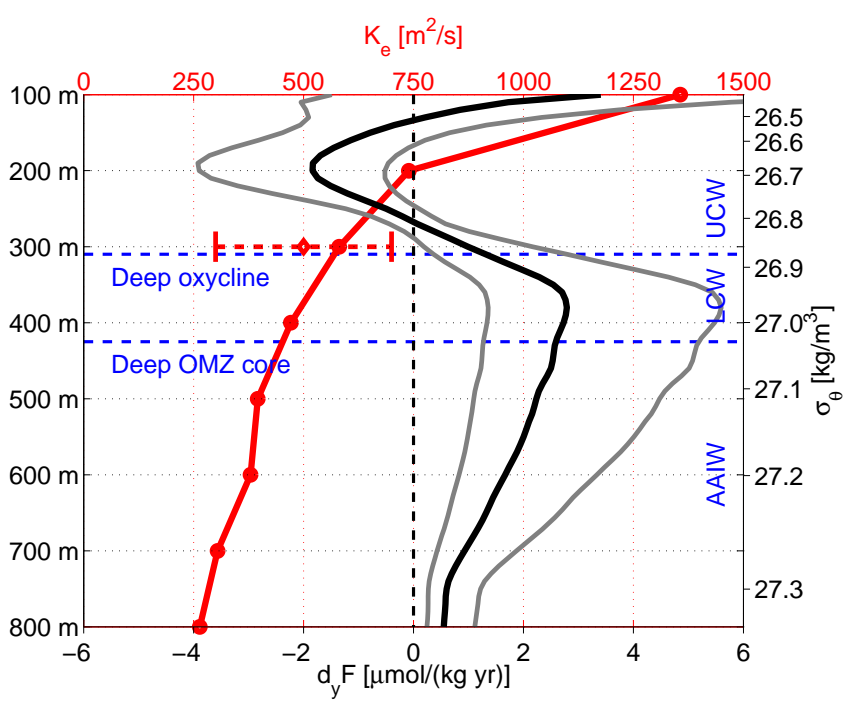

Figure 14. Eddy diffusivity as estimated from moored and shipboard observations (red circles, red line, upper axis) and from the tracer release experiment (red diamond with error bar, upper axis) as function of depth (left axis) or potential density (right axis). Also shown is the mean isopycnal meridional eddy-driven oxygen supply (black line, lower axis) for the open ocean ETNA OMZ with error levels (grey lines, lower axis) that were calculated from both the error of the curvature of the meridional oxygen distribution $(95 \%$ confidence) and the error of the eddy diffusivity (factor of 2 assumed). Blue dashed lines mark the depths of the deep oxycline and of the core of the deep OMZ that separate layers of upper and lower CW, and AAIW.

sponding error was derived both from the error of the curvature of the meridional oxygen distribution ( $95 \%$ confidence) and the error of the eddy diffusivity (factor 2 assumed following Ferrari and Polzin, 2005).

The tropical and subtropical oceans are generally assumed to be associated with an anisotropic horizontal eddy diffusivity (Banyte et al., 2013; Eden, 2007; Eden and Greatbatch, 2009; Kamenkovich et al., 2009) with larger horizontal eddy diffusivities in the zonal than in the meridional direction. Nevertheless, at the depth of the OMZ core, we consider the zonal eddy flux divergence small compared to the meridional eddy flux divergence, since the 2nd derivative of oxygen is an order of magnitude smaller in the zonal than the meridional direction.

\subsection{Advection}

We now turn to the remaining ventilation term in the budget, that is, the term associated with zonal advection (meridional advection is assumed to be negligible). We are only able to quantify this term as a residual. A rigorous determination of the advection term would require mean sections around a closed box to fulfil mass balance within the box. This cannot be achieved with the present observing system. However, our measurements along $23^{\circ} \mathrm{W}$ confirm that the advection term 

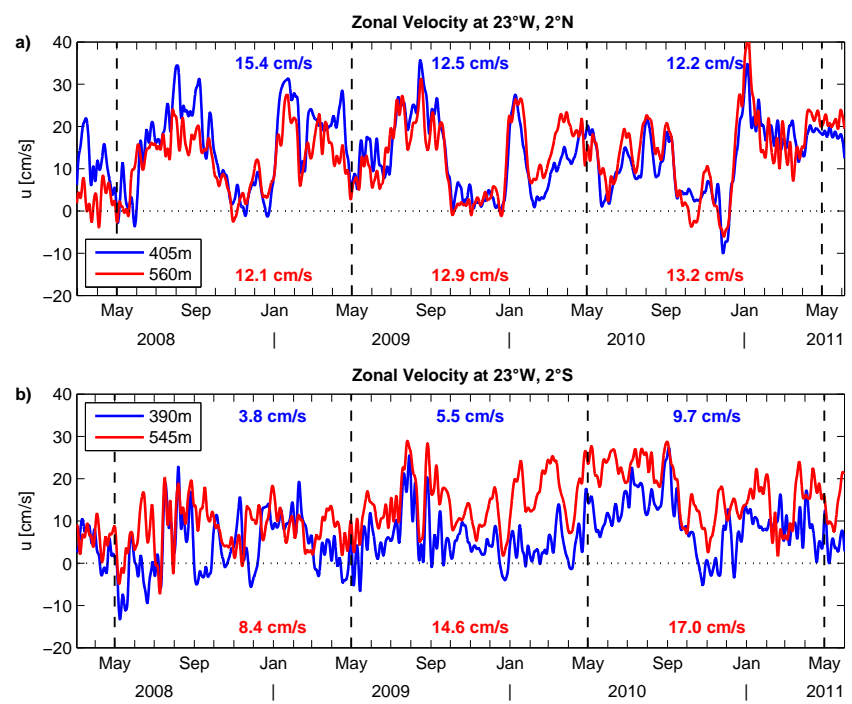

Figure 15. Zonal velocity from moored observations at $23^{\circ} \mathrm{W}, 2^{\circ} \mathrm{N}$ (a) and $23^{\circ} \mathrm{W}, 2^{\circ} \mathrm{S}$ (b) at about $400 \mathrm{~m}$ (blue lines) and $550 \mathrm{~m}$ (red lines). Blue and red numbers represent annual mean velocities at about 400 and $550 \mathrm{~m}$ in depth, respectively. Dashed vertical lines mark time periods used for the calculation of annual means; dotted horizontal line marks zero velocity.

is a major player in the ventilation of the $\mathrm{OMZ}$, especially above $400 \mathrm{~m}$ in depth.

The key factor for carrying the relatively oxygen-rich waters eastwards from the western boundary is the presence of a series of latitudinally stacked zonal jets that are now known to be an ubiquitous feature of the tropical oceans (e.g. Maximenko et al., 2005; Qiu et al., 2013). Near the Equator in the Atlantic, these jets are confined below the Equatorial Undercurrent (EUC), but away from the Equator they extend to the surface, and at all latitudes they tend to have a strong depth-independent (barotropic) structure (Fig. 6). Brandt et al. (2010) suggested that a reduction in the strength of these jets north of the Equator was a factor in the recent reduction in oxygen within the OMZ. The influence these jets have on the meridional oxygen distribution can clearly be seen in Fig. 13 of Hahn et al. (2014) that shows the eddydriven meridional oxygen supply. The red and blue alternating bands above $400 \mathrm{~m}$ in depth in that figure indicate a latitudinal redistribution of oxygen by mesoscale eddies, i.e. an oxygen gain for westward jets and an oxygen loss for eastward jets. It is clear from this figure that the zonal jets must play an important role in ventilating the upper $400 \mathrm{~m}$ of the water column in the latitude band (north of $6^{\circ} \mathrm{N}$ ) of the OMZ. Looking at the equatorial region, the oxygen source (shown in blue) associated with the eastward jets, centred near $2^{\circ} \mathrm{N}$ and $2^{\circ} \mathrm{S}$ below $350 \mathrm{~m}$ in depth, can also be seen in Fig. 13 of Hahn et al. (2014). These so-called "flanking jets" are clearly an important ventilation pathway for maintaining the oxygen maximum at the Equator, as discussed further below.
The ventilation of the equatorial region, where there is a local oxygen maximum, has been studied by Brandt et al. (2012) using an advection-diffusion model. The role of the equatorial deep jets (EDJ; see Brandt et al., 2008, and Brandt et al., 2011) was also discussed in that paper. As can be seen from Fig. 6, the "flanking jets" are much stronger than the off-equatorial zonal jets noted earlier. Ascani et al. (2010) have suggested that these jets are maintained by Yanai waves, generated at the surface (possibly by instability of the energetic near-surface flow field forming tropical instability waves: von Schuckmann et al., 2008; Jochum et al., 2004), which break at depth. The jets show considerable variability (see Fig. 15) on monthly timescales, but are almost always unidirectional (especially in the Northern Hemisphere); their longitudinal dependence along the Equator is currently uncertain. The EDJ are also thought to be generated by downward propagating Yanai waves, in this case by barotropic instability of these waves as discussed by Hua et al. (2008) (see also d'Orgeville et al., 2007 and Ménesguen et al., 2009). The EDJ show downward phase propagation but upward energy propagation, consistent with the above theory, and lead to variability with a roughly 4.5 year period throughout the water column within 2 degrees latitude on either side of the Equator and above about $3000 \mathrm{~m}$ in depth (Brandt et al., 2011). As shown by Brandt et al. (2012), there is evidence of a corresponding 4.5 year variability in oxygen levels in the same region (Fig. 8, Equator), with variability at $300 \mathrm{~m}$ in depth at $23^{\circ} \mathrm{W}$ on the Equator having a range comparable to the range of the mean oxygen level along the Equator across the entire Atlantic.

\section{Consumption}

Oxygen consumption is a key mechanism for the formation of OMZs (Sverdrup, 1938; Wyrtki, 1962) and, although being a prominent part of the local oxygen budget of the OMZs, it is among the poorest constrained ones. We will consider here only the net consumption that is the combined effect of removal and production of oxygen. Removal of oxygen is related to the metabolism of marine life as well as to elementary chemical reactions, whereas production of oxygen is related to photosynthesis and as such is confined to the euphotic zone (e.g. Martz et al., 2008). We will focus in this section on pelagic oxygen consumption; removal of oxygen from the water column by uptake at the sediment-water interface will be discussed in Sect. 6 .

Direct observations of oxygen in situ respiration are rare, primarily due to technical difficulties (e.g. Holtappels et al., 2014). The most commonly applied approach to quantifying time- and space-integrated oxygen removal and production processes is through an apparent oxygen utilisation rate (AOUR; e.g. Riley, 1951; Jenkins, 1982, 1998; Karstensen et al., 2008; Martz et al., 2008; Stanley et al., 2012). The AOUR is calculated as the ratio between the 
apparent oxygen utilisation (AOU) and age $(\tau)$. Hereby, AOU is determined as the difference between the air saturation value of dissolved oxygen (e.g. Weiss, 1970) at a given temperature and salinity (surface water saturation is commonly assumed to be $100 \%$ ) and the observed in situ oxygen concentration. The ageing of the water starts when a water parcel leaves the surface mixed layer $(\tau=0)$ and enters the ocean interior. As the ageing is closely linked to the ventilation process, the age is also called the ventilation age. In many cases the ventilation age is calculated from transient tracers (e.g. CFC-11, CFC-12, $\mathrm{CCl}_{4}, \mathrm{SF}_{6}$ ). Under the assumption of a given surface saturation (typically $100 \%$ ), the observed in situ tracer concentration is converted back to an equivalent atmospheric mixing ratio via its solubility function. The comparison with the respective tracer atmospheric time history finally yields the tracer age. For radioactive tracers (e.g. ${ }^{3} \mathrm{He} /{ }^{3} \mathrm{H},{ }^{39} \mathrm{Ar}$ ), a slightly different approach is used, but still requires the knowledge of surface concentrations or surface input functions (e.g. Roether et al., 2013; Lu et al., 2014). AOUR calculated using the tracer age follows an exponential decay with depth, at least for oceanic regions dominated by advection (Riley, 1951; Jenkins, 1982, 1998; Karstensen et al., 2008; Martz et al., 2008; Stanley et al., 2012). Such a structure supports the view that consumption is primarily a function of downward sinking particles (Martin et al., 1987).

The basic concept behind a ratio of along pathway oxygen removal and along pathway age increase assumes that the two quantities are consistently altered by ocean transport processes, e.g. it is assumed that as age increases so does AOU (Thiele and Sarmiento, 1990). While this seems to be a reasonable assumption for the ventilated gyre, it is questionable for the shadow zone where the OMZs are located. Here, diapycnal mixing (Fischer et al., 2013) and complex advection/lateral mixing patterns (Brandt et al., 2010; Hahn et al., 2014) have a strong influence on the local oxygen transport and water parcels from multiple source regions with different ventilation ages and along-path integrated oxygen consumption meet and mix.

Water mass composition and water ages can also be considered in a TTD approach (Haine and Hall, 2002), but limitations exist for non-steady state tracers (such as transient tracers). The TTD concept acknowledges the shortcomings in age calculations, which assign a single tracer age to a water parcel, and provides a framework to characterise the ventilation age more realistically (e.g. Waugh et al., 2004) by providing a mean age of the TTD. In a study using a transient tracer data set (up to 2009), Schneider et al. (2012) showed for the ETNA that the TTD obeys an inverse Gaussian function with the two moments $\Gamma$ and $\Delta$ being equal $(\Delta / \Gamma=1)$, where $\Gamma$ is the mean age and $\Delta$ defines the width of the TTD. In the limit of $\Delta / \Gamma=0$, the mean age of the TTD equals the single tracer age.

Here an extended set of CFC-12, $\mathrm{SF}_{6}$ and oxygen data collected in the ETNA OMZ is used to apply the TTD approach

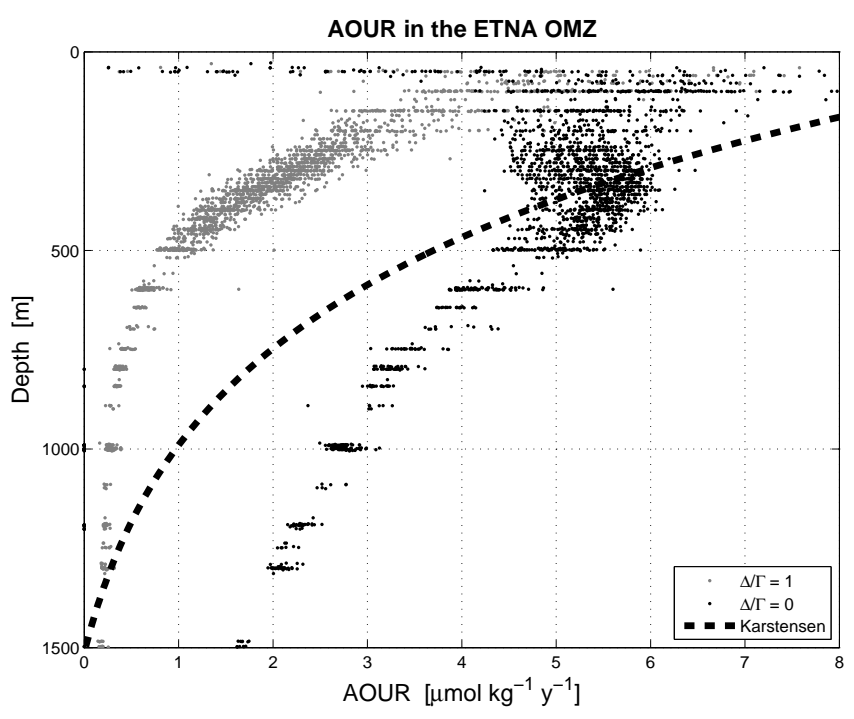

Figure 16. AOUR in the ETNA OMZ (between 4 and $14^{\circ} \mathrm{N}$ and east of $32^{\circ} \mathrm{W}$ ). The AOUR was calculated using the TTD approach with two different assumptions about mixing: black dots corresponds to no mixing, $\Delta / \Gamma=0$; grey dots to moderate mixing, $\Delta / \Gamma=1$. The dashed line marks AOUR as obtained by Karstensen et al. (2008) using CFC-11 ages from the ventilated gyre.

for exploring the oxygen consumption rate. Using CFC-12 and $\mathrm{SF}_{6}$ data $\left(\mathrm{SF}_{6}\right.$ preferentially used if available and $\mathrm{CFC}-$ 12 if $\mathrm{CFC}-12>450 \mathrm{ppt}$, i.e. corresponding to atmospheric mixing ratios at about the end of the near-linear atmospheric increase) the AOUR is calculated using two different $\Delta / \Gamma$ ratios (Fig. 16). Note that the AOUR for $\Delta / \Gamma=0$ is larger than values reported previously (Fig. 16) that were obtained by using a single tracer age concept applied to data collected in the ventilated gyre (e.g. Karstensen et al., 2008).

The two estimates for $\Delta / \Gamma=0$ and $\Delta / \Gamma=1$ represent an upper and lower limit of the AOUR within the ETNA OMZ, respectively. A shortcoming of the TTD concept in this region is its one-dimensionality (single water mass), i.e. it only considers the along-isopycnal mixing of parcels of a single source water mass, which might have encountered different advection and diffusion pathways and thus differ in age and AOU. The influence of diapycnal mixing (Fischer et al., 2013) and the mixing of two or more source waters (e.g. North and South Atlantic Central Water) (Kirchner et al., 2009; Brandt et al., 2010) is not considered by the TTD concept, which probably leads to a bias of the resulting AOUR. In fact our AOUR values for $\Delta / \Gamma=1$ are lower than those calculated by Stanley et al. (2012) for the ventilated gyre region of the western North Atlantic close to Bermuda, where they used the TTD approach with $\Delta / \Gamma=1$ on tritium $\left({ }^{3} \mathrm{H}\right)$ and ${ }^{3} \mathrm{He}$ measurements. They derived AOUR values close to $5 \mu \mathrm{mol} \mathrm{kg}^{-1} \mathrm{yr}^{-1}$ for the potential density level of $27.0 \mathrm{~kg} \mathrm{~m}^{-3}$ that were similar to AOUR values obtained by Karstensen et al. (2008) using CFC-11 ages. For 


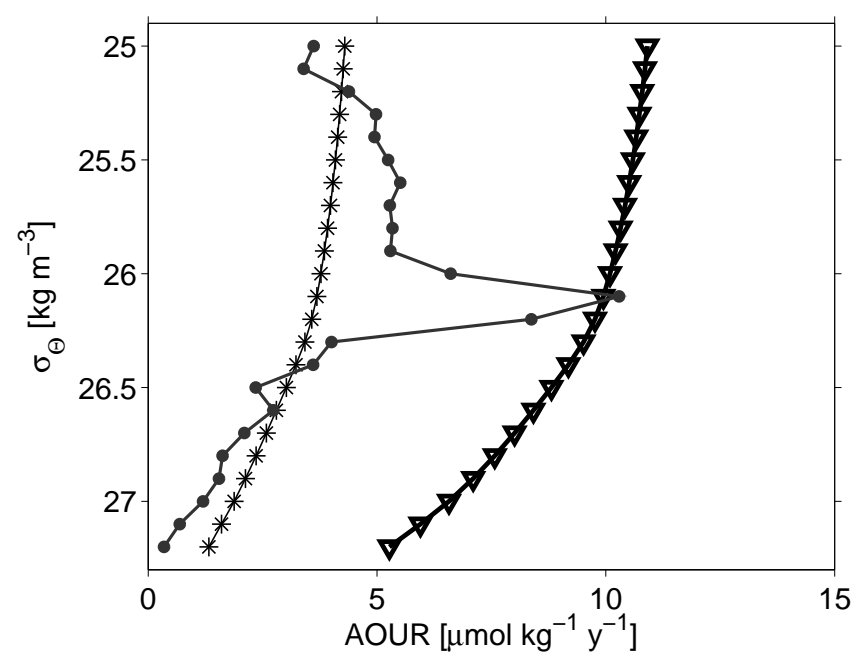

Figure 17. Three estimates of AOUR as a function of density: Schneider et al. (2012) used the TTD approach for the ETNA (stars), Karstensen et al. (2008) used CFC-11 water ages from the ventilated gyre only (triangles), and based on the ratio of North Atlantic mean AOU for isopycnal volumes and the corresponding reservoir ages (black dots, see further details, e.g. reservoir ages and volumes, in Karstensen et al., 2008; Figs. 9 and 10).

the same density level that is close to the OMZ core depth at roughly $400 \mathrm{~m}$, we derived AOUR values of only about $1.5 \mu \mathrm{mol} \mathrm{kg} \mathrm{kgr}^{-1}$ using the TTD approach with $\Delta / \Gamma=1$. The main differences are that the waters off Bermuda are much better represented by a single water mass and that they are significantly younger with a TTD derived mean age of a few tens of years. Waters in the ETNA OMZ instead are a mixture of water masses from multiple sources, some of which might be rather old, resulting in a mean TTD age of 120-180 years (Fig. 7).

Another approach to estimating the large-scale AOUR is based on the reservoir age (Bolin and Rodhe, 1973), which is derived as the ratio of the total volume of the reservoir for an isopycnal range and the corresponding ventilating flux (that is, the subduction rate). The AOUR based on the reservoir age is then given by the ratio of the mean AOU of the isopycnal volume and the corresponding reservoir age. For the ETNA OMZ, the AOUR obtained using the reservoir ages of Karstensen et al. (2008) is for some density classes rather similar to the TTD approach with $\Delta / \Gamma=0$, while for the well-ventilated isopycnal volumes ( 26.1 to $26.2 \mathrm{~kg} \mathrm{~m}^{-3}$; see also Fig. 9 in Karstensen et al., 2008), it is closer to the AOUR from the tracer age approach (Fig. 17).

\section{Processes at the continental margin}

Processes contributing to the ventilation of OMZs at the continental margin are advective oxygen transport within the eastern boundary current system, upper-ocean diapycnal oxygen supply due to increased turbulent mixing on the continental slope and shelf, and eddy-driven isopycnal oxygen transport. In comparison to the open ocean OMZs, the consumption of oxygen at the continental margin is generally enhanced due to high pelagic primary production, which in turn results in an increased respiration associated with sinking particles in the water column and at the sediment-water interface. These processes are largely responsible for the regional oxygen distribution particularly defining the shape of the shallow OMZ in the ETNA. Along the eastern boundary, oxygen concentrations within the shallow OMZ decrease towards the north reaching a minimum at about $20^{\circ} \mathrm{N}$ (Fig. 4). For the deep OMZ, minimum oxygen levels at the continental margin are found south of $16^{\circ} \mathrm{N}$ (Machin and Pelegri, 2009).

\subsection{Upwelling and circulation}

The continental margin off Mauritania and Senegal is part of the Canary eastern boundary upwelling system that extends from the northern tip of the Iberian Peninsula at $43^{\circ} \mathrm{N}$ to south of Dakar at about $10^{\circ} \mathrm{N}$ (e.g. Mittelstaedt, 1991). Due to changes in wind forcing associated with the migration of the Intertropical Convergence Zone, coastal upwelling off Mauritania and Senegal exhibits a pronounced seasonality. Here winds favourable to upwelling prevail primarily from December to April. The seasonality in upwelling and associated primary production must be reflected in oxygen consumption and thus in water-column oxygen concentrations at the continental margin.

The ventilation of the waters above the continental margin occurs primarily through the Mauritania Current in the surface layer and the Poleward Undercurrent below. Both currents transport relatively oxygen-rich South Atlantic Central Water, which is supplied by the eastward flowing NECC and NEUC (Figs. 1, 4), northward into the upwelling region. Often, these two currents are not distinct from each other (e.g. Peña-Izquierdo et al., 2012). Usually, the Poleward Undercurrent is found attached to the continental slope between 50 and $300 \mathrm{~m}$ in depth, but it may extend as deep as $1000 \mathrm{~m}$ (Mittelstaedt, 1983; Barton, 1989; Hagen, 2001; Peña-Izquierdo et al., 2012). Average along-shore velocities from $18^{\circ} \mathrm{N}$ (Fig. 5) show a predominantly poleward flow in the upper $300 \mathrm{~m}$ over the continental slope of Mauritania exceeding $0.05 \mathrm{~m} \mathrm{~s}^{-1}$. However, the effect of the eddy field and other variability on the mean flow is clearly not averaged out, due to the small number of available ship sections.

Previous studies showed that the Mauritania Current exhibits a seasonal behaviour (Mittelstaedt, 1991), which was found to be associated with the seasonality of the NECC, suggesting that the ventilation of the water masses above the continental margin also varies seasonally. In boreal winter and early boreal spring, when the NECC is weak, the Mauritania Current only reaches latitudes of about $14^{\circ} \mathrm{N}$, while in boreal summer and early boreal autumn, due to the strengthening of the NECC and the relaxation of the northeast trade 
winds, the Mauritania Current reaches latitudes of about $20^{\circ} \mathrm{N}$ (Mittelstaedt, 1991; Stramma et al., 2008a). Besides the seasonal cycle, the flow variability off Mauritania and Senegal is influenced by intraseasonal coastal-trapped waves partly originating in the equatorial wave-guide (Polo et al., 2008). However, associated sea level anomalies are substantially weaker in the North Atlantic compared to the same latitude band in the South Atlantic. A strong influence of coastal-trapped waves on the oxygen distribution on the shelf of the ETNA as evidenced for the eastern boundary upwelling systems of the South Pacific and South Atlantic (Gutierrez et al., 2008; Monteiro et al., 2011) could so far not be shown.

Several studies have indicated that most of the water carried northward at the continental margin of Mauritania recirculates in the region off Cape Blanc at about $21^{\circ} \mathrm{N}$ within a cyclonic gyre (Mittelstaedt, 1983; Peña-Izquierdo et al., 2012). This circulation pattern is in agreement with the regional distribution of oxygen levels within the shallow oxygen minimum that exhibits the lowest oxygen concentrations at the continental margin and offshore just south of Cape Blanc (Peña-Izquierdo et al., 2012).

\subsection{Benthic oxygen uptake}

Oxygen uptake within the benthic region (i.e. the sediment and the immediately overlying water) is largely controlled by sediment oxygen consumption and can be a significant sink for oxygen from the water column above. In contrast to the difficulties of direct measurement of pelagic oxygen consumption, local measurements of sediment oxygen uptake are relatively straightforward for performing with a variety of techniques. Recent developments in measurement techniques include the use of benthic chambers, eddy-correlation techniques, multi-sensor microprofilers and benthic observatories (e.g. Glud, 2008). Total benthic oxygen uptake (TOU), which includes all processes consuming oxygen within the benthic region, is commonly measured by enclosure techniques such as benthic chambers. With these systems, the initial oxygen decrease of an overlying well-mixed water phase is approximately linear. TOU is then calculated based on the rate of oxygen decrease, accounting for the enclosed area and water volume. TOU rates have recently been measured in the upper $1000 \mathrm{~m}$ on the continental slope and shelf off Mauritania using benthic chambers attached to landers (Dale et al., 2014). The reported TOU rates that are quantified in terms of oxygen fluxes into the sediments were as high as $10 \mathrm{mmol} \mathrm{m}^{-2} \mathrm{~d}^{-1}$ in depths between 50 and $100 \mathrm{~m}$, and decreased quasi-exponentially to about $3 \mathrm{mmol} \mathrm{m}^{-2} \mathrm{~d}^{-1}$ at a depth of $1000 \mathrm{~m}$. To compare TOU rates to pelagic oxygen consumption, we have to apply the TOU to a water volume with a given in situ density: the consumption within a $1 \mathrm{~m}$ thick layer above the bottom due to TOU is 3 orders of magnitudes larger when compared to pelagic oxygen consumption occurring at similar depths. This is due to the volume- specific production and degradation of organic material in surface sediments, which supports high densities of microbes and metazoans (Glud, 2008). In shelf areas, it is estimated that 10 to $50 \%$ of the pelagic primary production reaches the sediment (Canfield, 1993; Wollast, 1998), and benthic remineralisation plays a key role in this region for the recycling of nutrients and burial of carbon.

Although the benthic oxygen consumption due to TOU at the shelf greatly exceeds the pelagic oxygen consumption, benthic processes play a minor role for oxygen depletion within larger volumes such as that of the deep OMZ. To illustrate this, we assume that oxygen-depleted water masses are laterally exchanged between the shelf and the open ocean. Between 300 and $600 \mathrm{~m}$ in depth, the continental margin has a typical average topographic slope of about $4 \%$, corresponding to $25 \mathrm{~m}$ shelf width per $1 \mathrm{~m}$ depth change. Assuming a TOU of $5 \mathrm{mmol} \mathrm{m}^{-2} \mathrm{~d}^{-1}$ results in an oxygen depletion by the sediments of $125 \mathrm{mmol} \mathrm{d}^{-1}$ per $1 \mathrm{~m}$ depth range and $1 \mathrm{~m}$ along-shelf distance. Using the range of pelagic oxygen consumption determined in Sect. 5 ( 1 to $5 \mu \mathrm{mol} \mathrm{kg}^{-1} \mathrm{yr}^{-1}$ ) and the corresponding in situ density, the equivalent water volume resulting in an oxygen depletion of $125 \mathrm{mmold}^{-1}$ would be $44 \times 10^{3}$ to $9 \times 10^{3} \mathrm{~m}^{3}$, corresponding to distances from the shelf, where both processes have comparable influence, of 44 to $9 \mathrm{~km}$. In other words, pelagic oxygen consumption within the deep OMZ, typically extending about $1000 \mathrm{~km}$ offshore, is 1 to 2 orders of magnitude larger than benthic oxygen consumption due to oxygen fluxes into the continental slope sediments. Reduced topographic slopes at shallower depths suggest a more important role of benthic oxygen uptake for the shallow OMZ, which is characterised by a minimum oxygen concentration close to the continental margin and is not as widespread as its deeper counterpart (cf. Figs. 3, 4).

\subsection{Diapycnal oxygen fluxes at the continental margin}

Diapycnal mixing on continental slopes and shelves is often found to be elevated due to tides interacting with topographic boundaries that accelerate an energy cascade from large-scale open ocean tides to small-scale turbulence (e.g. Sandstrom and Oakey, 1995). As shown by Schafstall et al. (2010), diapycnal mixing along the upper continental slope and lower shelf region off Mauritania is strongly elevated due to the presence of nonlinear internal waves that are boosted by the interaction of the barotropic tide with critically sloping topography (e.g. Holloway, 1985). Diapycnal nutrient fluxes calculated for the upwelling region are amongst the highest reported to date (Schafstall et al., 2010).

To assess the role of diapycnal mixing for ventilating the upper layer of the ocean above the continental slope, the diapycnal oxygen flux was calculated from 112 microstructure profiles collected over the continental slope between 500 and $100 \mathrm{~m}$ in water depth at $18^{\circ} \mathrm{N}$ along with CTD- $\mathrm{O}_{2}$ profiles from two boreal winter cruises on the shelf of Mauritania 
(for details of the data set used, see Schafstall et al., 2010). Elevated mixing was found in a region with water depths shallower than $500 \mathrm{~m}$ (Schafstall et al., 2010). Within this region, the diapycnal flux of oxygen from the mixed layer into the stratified ocean is $73 \mathrm{mmol} \mathrm{m}^{-2} \mathrm{~d}^{-1}$, with upper and lower $95 \%$ confidence limits determined from Gaussian error propagation (Ferrari and Polzin, 2005; Schafstall et al., 2010) being 105 and $44 \mathrm{mmol} \mathrm{m}^{-2} \mathrm{~d}^{-1}$, respectively. The diapycnal oxygen flux thus exceeds the benthic oxygen uptake by a factor of about 7 . The diapycnal flux profile exponentially decays with depth, and the downward oxygen flux is reduced to less than $10 \mathrm{mmol} \mathrm{m}^{-2} \mathrm{~d}^{-1}$ at a depth of $60 \mathrm{~m}$ below the mixed layer, which has an average thickness of about $20 \mathrm{~m}$. Diapycnal mixing is thus able to supply the oxygen fully that is required by the benthic oxygen uptake for water depths shallower than about $80 \mathrm{~m}$. At about $150 \mathrm{~m}$ in depth, however, the diapycnal flux changes sign due to the presence of the shallow OMZ, and oxygen here is essentially fluxed upward, although at low rates. Thus, oxygen from the sea surface cannot contribute to ventilating the deeper water column via diapycnal mixing.

It should be noted that the diapycnal oxygen flux divergence from the mixed layer to $60 \mathrm{~m}$ below the mixed layer yields a diapycnal oxygen supply of about $400 \mu \mathrm{mol} \mathrm{kg} \mathrm{yr}^{-1}$. In steady state other oxygen transport processes and consumption are required to balance this substantial oxygen supply. While vertical advection during the upwelling season might contribute to the balance, the oxygen supply due to other transport processes should be at least an order of magnitude lower in this region. The diapycnal oxygen supply to the upper thermocline can thus be used to define an upper limit of the oxygen consumption below the mixed layer. Such a consumption rate is, however, two orders of magnitude larger than the one estimated for the deep ocean as discussed above.

The results suggest that the high oxygen demand of the water column and the sediments within the upwelling region at shallow depths above the shallow OMZ may well be supplied from the surface via diapycnal mixing. At larger depths however, the continental slope must be ventilated via advective processes or isopycnal mixing. Nevertheless, although benthic oxygen uptake is an important local process decreasing oxygen levels in the bottom waters along the continental slope, it is negligible for the overall oxygen balance of the deep open ocean $\mathrm{OMZ}$.

\section{Long-term variability in ETNA OMZ}

OMZs of the tropical oceans expanded and intensified during the last 50 years. Decreasing oxygen trends were found for the 300-700 m layers of selected regions, with the strongest decrease in the ETNA of $-0.34 \pm 0.13 \mu \mathrm{mol} \mathrm{kg}^{-1} \mathrm{yr}^{-1}$ for the region $10-14^{\circ} \mathrm{N}, 20-30^{\circ} \mathrm{W}$ (Stramma et al., 2008b). The global analysis of observed changes in the oxygen content between 1960-1974 and 1990-2008 indicates a widespread and significant deoxygenation at about $200 \mathrm{~m}$ in depth in the tropical oceans (Stramma et al., 2010b). In the ETNA, this depth level corresponds to the intermediate oxygen maximum between the deep and shallow OMZs that is mainly ventilated by advection via zonal jets. A similar regional pattern of deoxygenation as for the $200 \mathrm{~m}$ level was found when vertically averaging oxygen changes over 200-700 m, albeit with a smaller amplitude (Stramma et al., 2010b).

One of the main questions regarding the observed oxygen trend is its possible relation to anthropogenic forcing that was suggested in a number of recent studies (Bopp et al., 2002; Keeling and Garcia, 2002; Plattner et al., 2002; Matear and Hirst, 2003; Oschlies et al., 2008; Schmittner et al., 2008; Frölicher et al., 2009; Keeling et al., 2010; Helm et al., 2011). Different mechanisms were suggested. Global warming results in decreasing oxygen solubility in surface waters, and due to the increasing upper ocean stratification, it might impact ocean circulation, subduction, and vertical mixing. Increased $\mathrm{CO}_{2}$ levels and ocean acidification might impact biogeochemistry and oxygen consumption as well. However, up to now, current coupled climate-biogeochemistry models fail to reproduce the observed regional patterns of the oxygen trend, thus prohibiting a solid conclusion to be drawn about driving mechanisms of the observed ongoing deoxygenation (Stramma et al., 2012).

Similarly, there remain open questions as to how much of the observed oxygen changes are related to internal variability of the ocean and the climate system and what the dominant mechanisms are. The analysis of dissolved oxygen concentrations at $300 \mathrm{~m}$ in depth in the tropical and South Atlantic Ocean south of $20^{\circ} \mathrm{N}$ obtained from stations collected during the 1925-1927 Meteor expedition and the period 1990-2008 showed different and sometimes reversed trends compared to the mean oxygen trends found for the last 50 years, which indicates that the trend is not continuous, but that multidecadal variations are superimposed (Stramma et al., 2012). The oxygen trend along $23^{\circ} \mathrm{W}$ for the period 1972-2013 indicates a widespread oxygen decline, with the strongest oxygen reduction above the core of the deep OMZ and north of the Cape Verde archipelago (Fig. 18). However, oxygen anomalies within two boxes covering the region of relatively high oxygen above the deep oxycline (150-300 m) and the core region of the deep OMZ (350-700 m) (Fig. 19) show varying trends over the extended period (1900-2013) and the more recent period of enhanced measurements from 2006 to 2013. Note that the trend over the extended period is dominated by data taken during the 1970s, 1980s and the period 2006-2013. For the intermediate oxygen maximum $(150-300 \mathrm{~m})$, there is only a weak oxygen decline during the period $1900-2013$ of $-0.8 \pm 0.5 \mu \mathrm{mol} \mathrm{kg}{ }^{-1} \mathrm{decade}^{-1}$, while during the period 2006-2013, a much stronger decline of $-14.3 \pm 6.9 \mu \mathrm{mol} \mathrm{kg}{ }^{-1}$ decade $^{-1}$ was observed. For the deep oxygen minimum $(350-700 \mathrm{~m})$, the long-term trend for the period $1900-2013$ is $-1.8 \pm 0.3 \mu \mathrm{mol} \mathrm{kg}^{-1} \mathrm{decade}^{-1}$, 


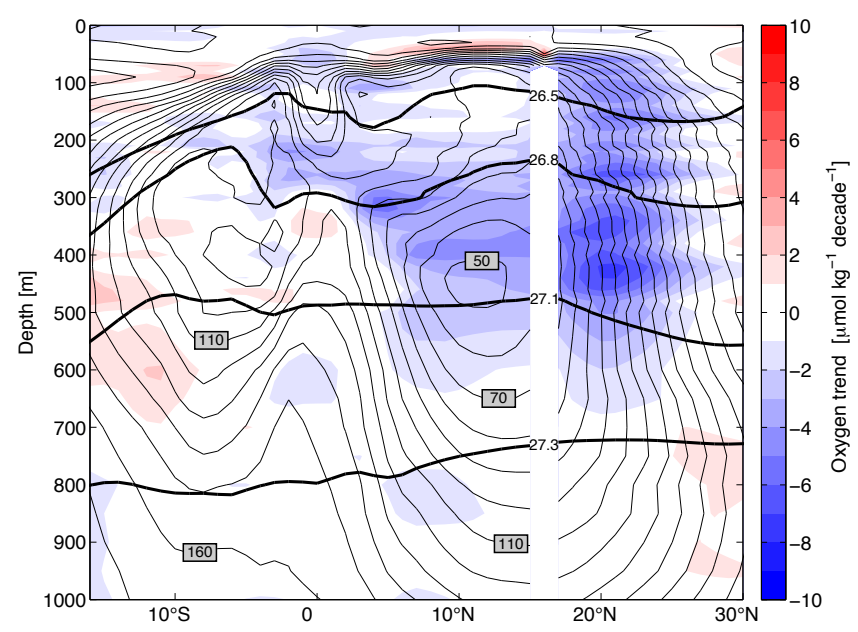

Figure 18. Oxygen trend along $23^{\circ} \mathrm{W}$ between 20 and $26^{\circ} \mathrm{W}$ and between 1972 and 2013 as obtained from the MIMOC climatology (Schmidtko et al., 2013). The trend was calculated on depth coordinates using oxygen anomalies relative to mean oxygen. Thin black contours mark mean oxygen $\left(\mu \mathrm{mol} \mathrm{kg}{ }^{-1}\right)$, thick black contours mark potential density $\left(\mathrm{kg} \mathrm{m}^{-3}\right)$, both from the MIMOC climatology.

while during the period 2006-2013, oxygen increased by $2.7 \pm 1.9 \mu \mathrm{mol} \mathrm{kg}^{-1} \mathrm{decade}^{-1}$. These variations in the obtained trends that are related to different timescales and depth ranges may help to understand the underlying mechanism of long-term oxygen changes.

Different mechanisms might contribute to decadal to multidecadal oxygen variability: (1) Decadal to multidecadal AMOC changes would result in changes in the water mass distribution in the tropical North Atlantic, as identified for example in simulations with ocean-atmosphere general circulation models (Chang et al., 2008). Shifts in the boundaries between Northern and Southern Hemisphere water masses would likely affect oxygen distribution as well. (2) The transport of Indian Ocean CW toward the Atlantic via the Agulhas leakage might have increased during the last decades due to a poleward shift in the Southern Hemisphere westerlies. Such a change was observable in the NBUC as an increase in CW salinity (Biastoch et al., 2009) and might be associated with changes in the oxygen distribution as well. (3) Changes in the strength of latitudinally stacked zonal jets as derived by Brandt et al. (2010) result in changes in the advective pathways to the ETNA OMZ, with likely the strongest impact in the upper $300-400 \mathrm{~m}$ of the water column (Hahn et al., 2014). (4) Changes in the strength and location of the winddriven gyres are a possible explanation for the long-term oxygen trends observed between $15^{\circ}$ and $30^{\circ} \mathrm{N}$ in Fig. 18. (5) The variability of ventilation efficiency, either through dynamics (subduction) or saturation (warming), is able to produce oxygen anomalies that propagate into the ocean's interior (Karstensen et al., 2008).
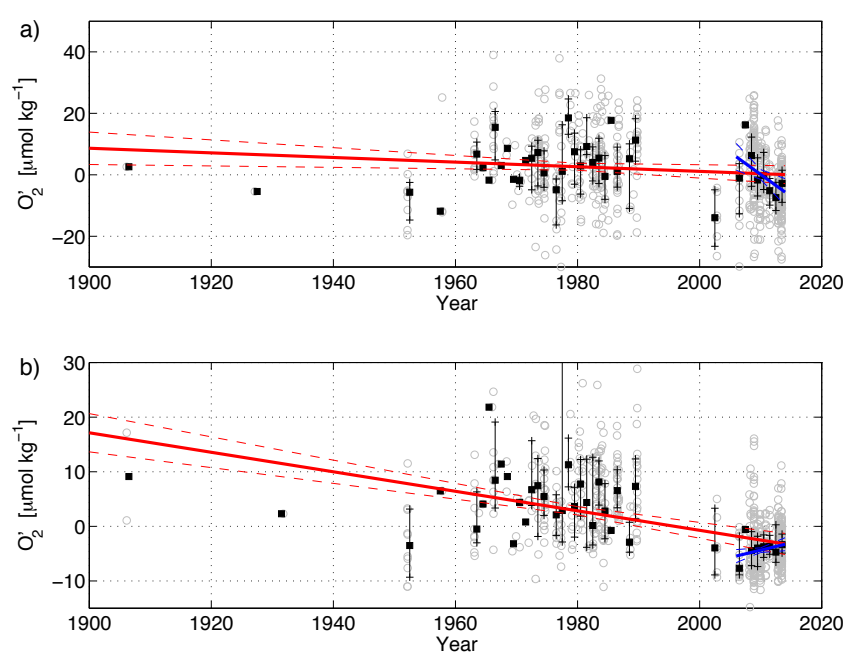

Figure 19. Oxygen anomalies for the region $9-15^{\circ} \mathrm{N}, 20-26^{\circ} \mathrm{W}$ and $150-300 \mathrm{~m}$ (intermediate oxygen maximum, upper panel) and 350-700 m (deep oxygen minimum, lower panel). Grey circles represent all available data, whiskers show interquartile range of data within each year and the black squares annual medians. Trends are calculated using annual medians weighted by the square root of available data within each year for the period 1900-2013 (solid red line) and 2006-2013 (solid blue line). The dashed lines mark the standard errors of the trends.

In the North Atlantic, indications exist of a North Atlantic Oscillation (NAO) influence on multidecadal oxygen variations (Stendardo and Gruber, 2012). A similar influence of the NAO (e.g. due to associated changes in the northeast trade winds) on the water masses of the ETNA OMZ has not yet been shown. However, multidecadal changes in the strength of Atlantic STCs were detected in assimilation model runs. These changes include a minimum STC-layer (about 50-300 m) convergence in the early 1970s and a maximum in the early 1990s (Rabe et al., 2008), which would affect the supply of newly subducted oxygen-rich water masses from the subtropics to the tropics.

\section{Similarities and differences between ETNA and ETSP OMZs}

Similar to the hypoxic ETNA OMZ, the suboxic ETSP OMZ is located in the shadow zone equatorward of the subtropical gyre, with the lowest oxygen levels near the shelf break. The most prominent differences between the two OMZs are that the ETSP OMZ covers a much wider region and that oxygen values in its core region are close to zero (Karstensen et al., 2008), while the typical large-scale oxygen minimum in the ETNA only recently reached values slightly below $40 \mu \mathrm{mol} \mathrm{kg}{ }^{-1}$ (Stramma et al., 2009). A continuation of the observed deoxygenation in the ETNA would turn the ETNA OMZ suboxic within a century; hence, it is worth looking at differences and similarities of the ETNA and the ETSP with 
regard to a possible shift of a hypoxic system to a suboxic system.

\subsection{The large-scale distribution}

Different from the ETNA with its Guinea Dome and the eastern tropical South Atlantic and eastern tropical North Pacific with similar domes, there is no dome in the ETSP (Kessler, 2006). Similar to the equatorial Atlantic, the equatorial Pacific is characterised by a local oxygen maximum and a system of eastward and westward currents (Figs. 2, 20). Near the Equator, the EUC, the NICC, and the SICC all carry water richer in oxygen than the adjacent westward flows (Stramma et al., 2010a). In the eastern Pacific, the Northern and Southern Subsurface countercurrents (NSCC and SSCC) are already low in oxygen and, different from the corresponding current bands in the Atlantic, do not provide oxygen-rich water to the OMZ. Near the Peruvian shelf, poleward and equatorward currents exist which supply equatorial and subtropical water to the eastern near-shelf regions (Fig. 2). The Chile-Peru Coastal Current (CPCC) and the Peru-Chile Current (PCC) flow equatorward in the near-surface layer close to the coast and farther than $\sim 150 \mathrm{~km}$ from the coast, respectively, while the Peru-Chile Undercurrent (PCUC) flows poleward in subsurface layers along the outer continental shelf and inner slope (Chaigneau et al., 2013). Based on a hydrographic survey off Peru in January and February 2009 and in combination with float data and model results, Czeschel et al. (2011) prepared a schematic of the intermediate circulation of the ETSP and its link to the OMZ. The centre of the OMZ is a stagnant-flow area and the mean currents at $400 \mathrm{~m}$ in depth in the open ocean ETSP are weak. Along the $\sim 86^{\circ} \mathrm{W}$ section, the lowest oxygen is observed between $6^{\circ} \mathrm{S}$ and $10^{\circ} \mathrm{S}$ centred at about $400 \mathrm{~m}$ in depth and on the isopycnal $\sigma_{\theta}=26.8 \mathrm{~kg} \mathrm{~m}^{-3}$. Along this isopycnal, the mean age is increased in the region of the low oxygen core, with a maximum mean age of about $300 \mathrm{yr}$ at about $11^{\circ} \mathrm{S}$, slightly poleward of the lowest oxygen concentration, and reduced near the Equator, with a mean age of about $200 \mathrm{yr}$ (Fig. 20).

\subsection{Mesoscale processes}

Mesoscale variability predominantly occurs as propagating Rossby waves and as nonlinear vortices or eddies. In particular, nonlinear vortices can trap and transport momentum, heat, mass and the chemical constituents of seawater, and therefore contribute to the large-scale water mass distribution (Chelton et al., 2007). Eddies are mainly generated by coastal flow instabilities that are influenced by remote equatorial forcing via coastal-trapped waves (Belmadani et al., 2012). They move westward from the coastal upwelling regions and hence carry shelf waters offshore. These eddies affect the regions' biogeochemical budgets, but also the primary productivity of the regions (Lachkar and Gruber, 2012), and seem to play an important role for the oxygen distri-
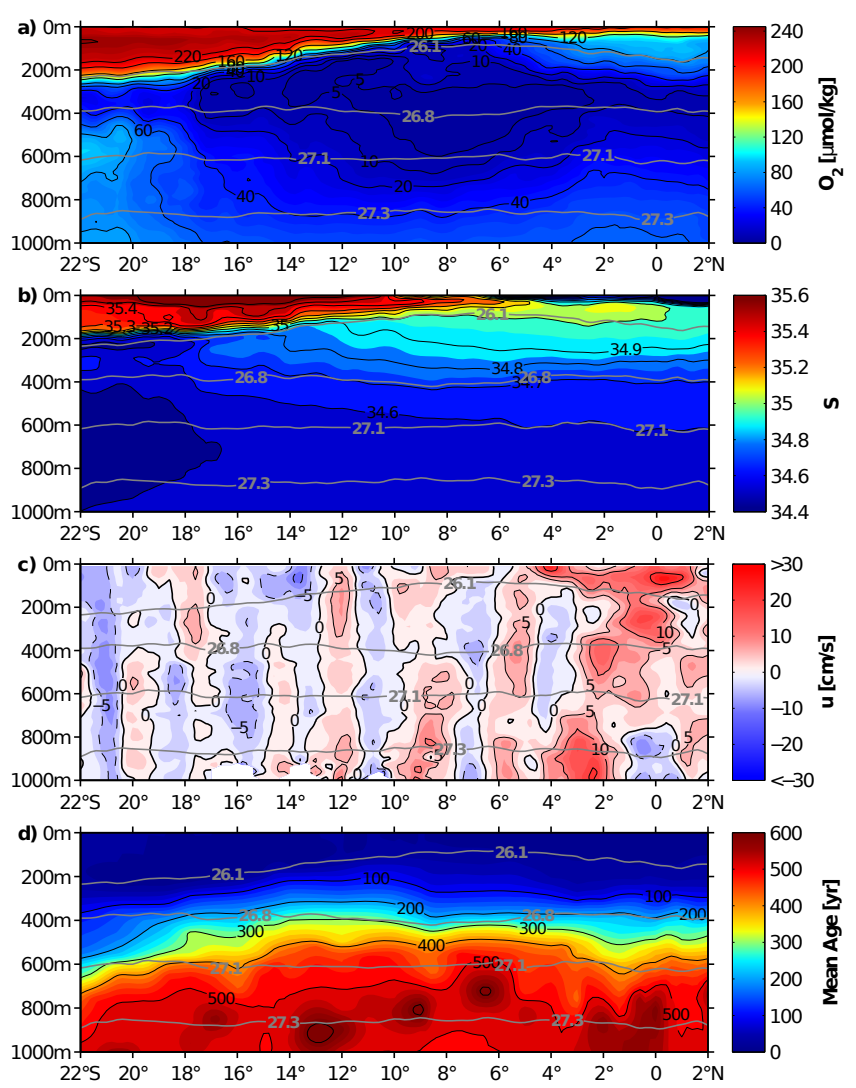

Figure 20. (a) Mean oxygen content, (b) salinity, (c) zonal velocity (positive eastward), and (d) mean age as obtained from meridional ship sections taken on three Pacific surveys along $\sim 86^{\circ} \mathrm{W}$ from 1993 to 2012 . Grey contours mark potential density $\left(\mathrm{kg} \mathrm{m}^{-3}\right)$. The mean age is based solely on data from 1993. Eastward current bands, marked by reddish colours, are generally associated with elevated oxygen content.

bution on the poleward side of the OMZs. In global satellite observations of nonlinear mesoscale eddies by Chelton et al. (2011), it turned out that in the ETNA south and east of the Cape Verde Islands, almost no eddies with lifetimes of more than 16 weeks were present, while in the ETSP, a large number of such eddies could be identified. Their occurrence extends close to the Equator and the Peruvian shelf, as can be seen in Fig. 4a of Chelton et al. (2011). Despite the inferred weak eddy activity in the ETNA, water mass anomalies including local oxygen minima at shallow depths just below the mixed layer have been found in cyclonic as well as in anticyclonic mode water eddies in this region (see Fig. 4, showing a few profiles with oxygen concentrations below $40 \mu \mathrm{mol} \mathrm{kg}^{-1}$ ). In the ETSP, a region of high eddy production is located just off the shelf at $15-16^{\circ} \mathrm{S}$, and strong eddies were described from a survey in November 2012. A strong anticyclonic mode water eddy located near the shelf of Peru at about $16^{\circ} \mathrm{S}$ showed a heat anomaly of $17.7 \times 10^{18} \mathrm{~J}$, a salt anomaly of $36.5 \times 10^{10} \mathrm{~kg}$ (Stramma et al., 2013) and 
an oxygen anomaly of $-10.0 \times 10^{16} \mu \mathrm{mol}$ (Stramma et al., 2014). Even in a mooring at $\sim 20^{\circ} \mathrm{S}, 85^{\circ} \mathrm{W}$, some $1500 \mathrm{~km}$ offshore, the passage of an anticyclonic mode water eddy carrying an oxygen anomaly of $-10.5 \times 10^{16} \mu \mathrm{mol}$ could be observed (Stramma et al., 2014). As eddies fall apart at the end of their lifetime, the anomalous hydrographic and biogeochemistry anomalies are redistributed in the ocean.

\subsection{Oxygen budgets}

A quantitative evaluation of the different terms of the oxygen budget of the tropical Pacific OMZ could not be performed so far. A rough estimate of the oxygen budget was instead given by Stramma et al. (2010a). They estimated the advective oxygen supply to the tropical Pacific OMZ from oxygen concentrations at, and zonal mass transport across, the $125^{\circ} \mathrm{W}$ meridian. The eastward mass transport associated with the EUC, SCCs and ICCs was estimated to be about $30 \times 10^{9} \mathrm{~kg} \mathrm{~s}^{-1}$. It was assumed that this mass transport is returned by the adjacent westward currents with a typical relative oxygen difference between eastward and westward currents of about $20 \mu \mathrm{mol} \mathrm{kg}{ }^{-1}$. The resulting net advective molar oxygen supply across $125^{\circ} \mathrm{W}$ is $0.6 \times 10^{6} \mathrm{~mol} \mathrm{~s}^{-1}$ (Stramma et al., 2010a). The diffusive supply was estimated through the climatological $60 \mu \mathrm{mol} \mathrm{kg}{ }^{-1}$ surface surrounding the tropical Pacific OMZ. Vertical and lateral oxygen gradients were evaluated at this surface and multiplied by a diapycnal diffusivity of $1 \times 10^{-5} \mathrm{~m}^{2} \mathrm{~s}^{-1}$ (Ledwell et al., 1998) and a horizontal eddy diffusivity of $500 \mathrm{~m}^{2} \mathrm{~s}^{-1}$ characteristic of the off-equatorial regions (Davis, 2005), respectively. Integrating these products over the surface area resulted in a vertical diffusive molar oxygen supply of $0.4 \times 10^{6} \mathrm{~mol} \mathrm{~s}^{-1}$ mostly through the upper surface, where the gradients are large, and in a lateral diffusive molar oxygen supply of $0.8 \times 10^{6} \mathrm{~mol} \mathrm{~s}^{-1}$ (Stramma et al., 2010a). The mass of the tropical Pacific OMZs between $30^{\circ} \mathrm{N}$ and $30^{\circ} \mathrm{S}$ with oxygen concentrations lower than $60 \mu \mathrm{mol} \mathrm{kg}{ }^{-1}$ is about $16 \times 10^{18} \mathrm{~kg}$. Dividing the estimates of molar supply by the mass leads to an advective oxygen supply of about $1.2 \mu \mathrm{mol} \mathrm{kg}^{-1} \mathrm{yr}^{-1}$, a lateral diffusive oxygen supply of $1.6 \mu \mathrm{mol} \mathrm{kg} \mathrm{yr}^{-1}$ and a vertical diffusive oxygen supply of $0.8 \mu \mathrm{mol} \mathrm{kg} \mathrm{gr}^{-1} \mathrm{yr}^{-1}$. The oxygen utilisation rate calculated to balance the net oxygen supply resulted in about $3.6 \mu \mathrm{mol} \mathrm{kg}-1 \mathrm{yr}^{-1}$. These rough estimates of the oxygen budget are far from being a reliable result; however, it points to an allocation of about $33 \%$ by advection, $45 \%$ by eddy mixing and $22 \%$ by vertical mixing. The calculation of the tropical Pacific oxygen budget differs from the calculation of the ETNA oxygen budget presented above: while advection along the Equator is included in the oxygen supply to the tropical Pacific OMZ, it is not in the ETNA OMZ. The budget of the ETNA OMZ included only the advective supply by zonal jets in the latitude range of the ETNA OMZ, while eddy mixing results in a meridional oxygen transport from the subtropical gyre in the north and the well-ventilated equatorial region in the south into the ETNA OMZ.

\subsection{Trends in oxygen}

As the ETSP OMZ is extremely low in oxygen, a decreasing trend is much more difficult to determine. Furthermore, data are sparse to investigate the trend. However, for the eastern Pacific equatorial region $\left(5^{\circ} \mathrm{S}\right.$ to $5^{\circ} \mathrm{N}, 105-$ $115^{\circ} \mathrm{W}$ ), a decrease of $0.13 \pm 0.32 \mu \mathrm{mol} \mathrm{kg} \mathrm{yr}^{-1}$ was described (Stramma et al., 2008b) for the 300-700 m depth layer for the last 50 years. The stronger decrease in oxygen in the ETNA compared to the ETSP is also visible from a global compilation of the trends of the last 50 years at $300 \mathrm{~m}$ in depth (Stramma et al., 2012).

On interannual to multidecadal timescales, oxygen variability in the ETSP is expected to be influenced by similar processes as those influencing the ETNA (see end of Sect. 7), albeit in response to the different large-scale climate modes that impact each ocean basin. In the Pacific, the multidecadal variability of the Pacific Decadal Oscillation (PDO) has the strongest influence on long timescales, while the El NiñoSouthern Oscillation (ENSO), which mainly influences the upper $350 \mathrm{~m}$ of the ETSP, is superimposed on long-term changes (Czeschel et al., 2012). The variability of the Pacific STCs exhibits an ENSO signature with strong meridional transport occurring during La Niña and weak meridional transport during El Niño, and hence is a possible mechanism for oxygen variability (Zilberman et al., 2013). Model runs indicate a control of decadal and bidecadal climate variability in the tropical Pacific by the off-equatorial South Pacific Ocean triggered by changes in wind stress curl in the South Pacific extratropics (Tatebe et al., 2013) as an additional mechanism for oxygen variability. Besides decadal to multidecadal changes in the ventilation processes, variations in the oxygen consumption have been suggested to result in changes in the suboxic and hypoxic volumes of the tropical and subtropical Pacific on similar timescales (Deutsch et al., 2011; Ito and Deutsch, 2013). From three sediment cores along the North American margin, Deutsch et al. (2014) proposed that centennial changes in the North Pacific anoxia are linked to changes in tropical trade winds and their effect on upwelling and biological production.

\section{Summary and discussion}

The aim of the present paper is to provide a synthesis of the results from recent efforts to understand the physical mechanisms underpinning the functioning of the OMZs in the eastern tropical oceans, with a focus on the ETNA. The paper is mainly based on observations in the ETNA and the ETSP. The ETNA was selected to perform a dedicated observational programme consisting of a large number of research cruises, continuous moored observations, and TREs to better 


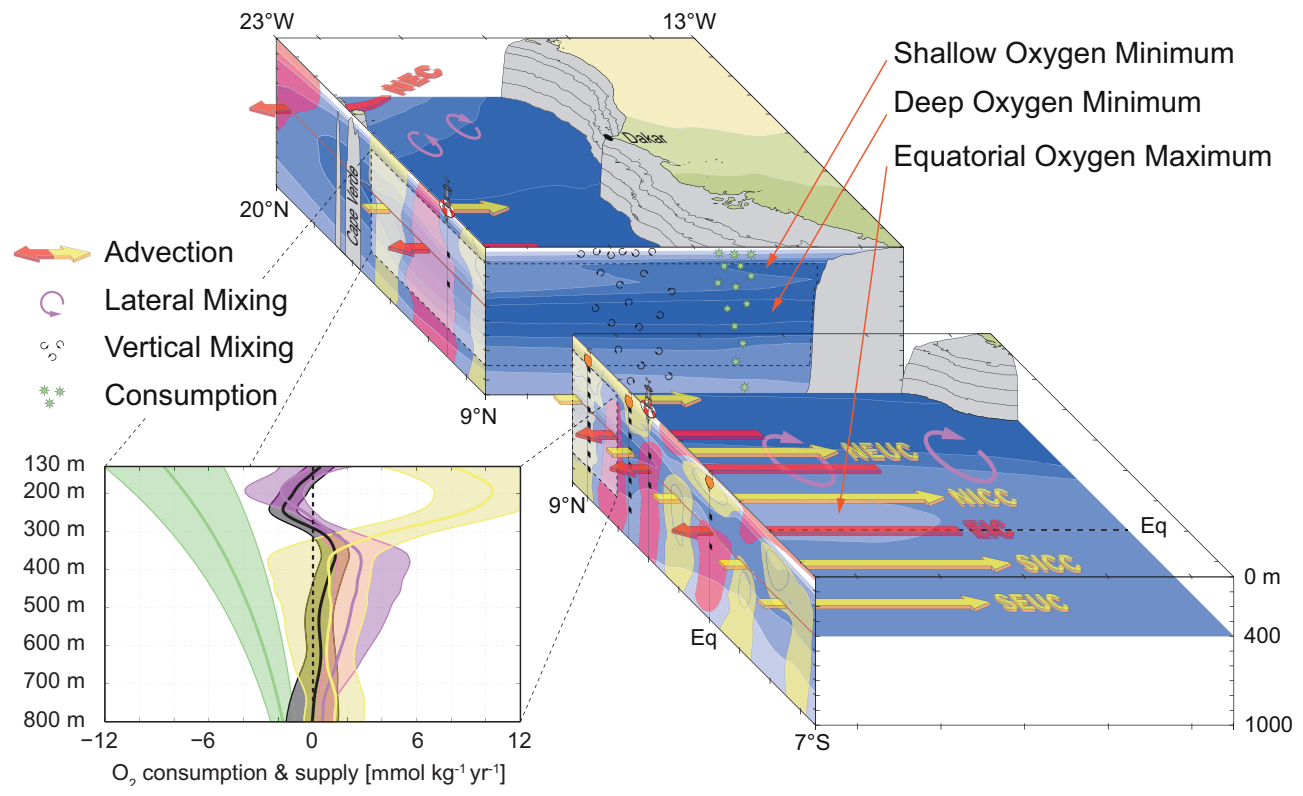

Figure 21. Schematic of the functioning of the ETNA OMZ and its oxygen budget. In the upper box, the oxygen distribution (bluish colours with dark/light blue corresponding to low/high oxygen) is shown at the sections along $23^{\circ} \mathrm{W}$ and $9^{\circ} \mathrm{N}$ and at a depth of $400 \mathrm{~m}$; in the lower right box it is shown at the section along $23^{\circ} \mathrm{W}$ and at a depth of $400 \mathrm{~m}$. Red and yellow areas at the $23^{\circ} \mathrm{W}$ section correspond to westward and eastward flow also marked by red and yellow arrows, respectively. The oxygen budget (lower left panel) includes physical supply by meridional (violet curve) and vertical mixing (black curve) as well as consumption after Karstensen et al. (2008) (green curve). The yellow curve is the residual of the other three terms, which is dominated by zonal advection. All error estimates (coloured shadings) are referred to a $95 \%$ confidence (except the isopycnal meridional eddy supply, where the error was estimated from both the error of the oxygen curvature (95\% confidence) and the error of the eddy diffusivity (factor 2 assumed)) (see further details in the text and in Hahn et al., 2014).

understand the role of circulation and mixing in the ventilation of the OMZ. Results are summarised in the schematic Fig. 21. The ETSP was selected to allow a comparison of a hypoxic and suboxic OMZ. There are substantial differences in the dynamics of the thermocline, with a dominance of seasonal over interannual modes of variability in the Atlantic as opposed to interannual modes dominating in the Pacific as well as in the ocean-shelf interactions, which are possibly associated with different climate sensitivities of the OMZs in both oceans. However, a comparison of the factors of deoxygenation in the Atlantic and the Pacific might help to assess the possibility of a shift in the ETNA from hypoxic to suboxic.

One of the main results of the recent efforts is a first quantification of the oxygen budget of the deep ETNA OMZ (Brandt et al., 2010; Fischer et al., 2013; Hahn et al., 2014) that is extended here to $800 \mathrm{~m}$ in depth (Fig. 21). Integrating the different terms of the oxygen budget of the ETNA OMZ (Hahn et al., 2014) into the depth range below the deep oxycline from 350 to $570 \mathrm{~m}$ yields a consumption (after Karstensen et al., 2008) mainly balanced by the divergence of the meridional eddy flux (about $60 \%$ ) and the divergence of the diapycnal flux $(20 \%)$. The obtained residual of about $20 \%$ can be ascribed in equal parts to the zonal advection and the long-term oxygen tendency as taken from Brandt et al. (2010). However, these are rough estimates. Most of the terms in the oxygen budget are associated with significant error, which particularly is the case for consumption and meridional eddy flux. Due to the TRE (Banyte et al., 2012) and repeated microstructure measurements (Fischer et al., 2013), the error in the diapycnal oxygen supply is comparatively small. The diapycnal oxygen supply is strongest slightly above the deep OMZ core, where it accounts for about one third of the oxygen supply required to balance consumption. There are, however, indications of regional variations in the diapycnal eddy diffusivity, with higher values over the seamount region (up to 1 order of magnitude) compared to the abyssal plains (Fig. 11), resulting also in a general increase in the diapycnal eddy diffusivity with depth (Fig. 12).

The contribution of the mean advection to the oxygen budget of the OMZ cannot be quantified from observational data. Instead, idealised advection-diffusion models were used to estimate this contribution (Brandt et al., 2010; Brandt et al., 2012). For these calculations, a basin-wide mean velocity field has to be prescribed based mainly on our knowledge of the mean flow along $23^{\circ} \mathrm{W}$. However, the zonal extent of the zonal jets, their deviation from a purely zonal flow, and their connection to the well-ventilated western boundary regime are crucial in this calculation, but are not well constrained by observations, which leads again to a large uncertainty in the 
contribution of the mean advection to the oxygen budget of the ETNA OMZ.

Consumption as the main oxygen sink in the oxygen budget of the OMZ is currently best estimated as the net consumption along a water mass path from the subduction region toward the OMZ (Haine and Hall, 2002; Karstensen et al., 2008; Schneider et al., 2012). The different methods presented here yield a range of possible net consumption rates differing by a factor of 2-4 (Fig. 17). Besides this uncertainty, AOUR represents a large-scale net consumption rate that cannot account for the regional inhomogeneity in consumption, for example due to higher productivity in coastal, equatorial or open ocean upwelling regions compared to the oligotrophic ocean. For a local oxygen budget as presented here, the local oxygen consumption within the OMZ is required, which could substantially differ from values representing an integrated oxygen consumption along pathways from the subduction regions, through the oligotrophic ocean (often including the western boundary regime) into the OMZs. Additionally, the assumption of a consumption profile decreasing exponentially with depth (Martin et al., 1987) might be invalid. Lutz et al. (2002) noted the inability to fit sediment trap data to a single exponential function. Due to vertical changes in the liability of organic matter, sinking rate, and mineral ballast effect, they therefore suggested using the sum of two exponential functions with different decays. Processes that would also contribute to a deviation from a single exponential profile include respiration associated with the daily vertical migration cycle of zooplankton (Bianchi et al., 2013) or oxygen consumption at the sediment-ocean interface and associated lateral spreading of low-oxygen waters. To tackle the problem of regional and temporal consumption variability, new targeted data-model approaches are required, including observations of sinking particles or incubations for estimating pelagic oxygen consumption.

The relative importance of the different terms affecting the oxygen budgets of the ETNA and ETSP OMZs appear to be similar. For both OMZs, the eastward advection of oxygenrich waters from the well-ventilated western boundary was found to be a dominant ventilation process. As the zonal currents are of similar strength in the tropical Pacific and Atlantic, the difference in the basin width of both oceans consequently results in lower oxygen concentrations and larger water mass ages in the eastern tropical Pacific (Fig. 20) compared to the eastern tropical Atlantic (Fig. 6).

Processes contributing to the oxygen budget at the eastern boundary include diapycnal mixing locally elevated due to tide-topography interaction, advective oxygen supply associated with (seasonally varying) eastern boundary circulation and coastal-trapped waves, mesoscale eddies favouring and redistributing oxygen anomalies, pelagic consumption and consumption at the sediment-ocean interface. Due to the high variability of most of these processes, both in space and time, the mean oxygen budget at the shelf is much less con- strained compared to the open ocean. Often these processes are characterised by strong physical-biogeochemical interaction. For example, the downward oxygen flux from the mixed layer due to elevated diapycnal mixing at the shelf (Schafstall et al., 2010) must be balanced at least partly by local consumption. The extremely large vertical oxygen gradient at the shelf in the ETSP (from saturated oxygen levels in the mixed layer to zero oxygen within a few metres below) suggests extremely high consumption rates just below the mixed layer. Other examples are isolated eddies generated by the instability of the eastern boundary current. Such eddies transfer shelf water properties toward the open ocean while transforming these properties (particularly oxygen) by enhanced physicalbiogeochemical interactions during their westward migration (Stramma et al., 2014). Their influence on the mean distribution of the shallow and deep OMZ could so far not be quantified. Dedicated process studies using mooring arrays, shipboard and multiple glider observations may help to elucidate the role of different processes in the eastern boundary oxygen budget.

The increase in the resolution of ocean circulation models improves the tropical circulation and associated oxygen distribution in the Atlantic (Duteil et al., 2014) and Pacific OMZs (Montes et al., 2014), suggesting that deficiencies in model physics largely contribute to the oxygen bias in coarser-resolution models. However, particularly the intermediate circulation (below $250 \mathrm{~m}$ ) is still underestimated by these high-resolution simulations in realistic settings. To identify the physical mechanism responsible for the mean and variable zonal jets, idealised high-resolution models have been employed (Ménesguen et al., 2009; Ascani et al., 2010; Qiu et al., 2013). Such idealised models could furthermore be used, by including oxygen in the simulations, to study the roles of mean and variable advection in maintaining the tropical OMZs and to identify the mechanisms driving oxygen variability on interannual to multidecadal timescales.

The oxygen decline in the ETNA OMZ during the last decades corresponds to about $10 \%$ of the oxygen sink due to consumption not balanced by ventilation processes. This is a substantial imbalance in the oxygen budget of the ETNA OMZ. The regional pattern along the $23^{\circ} \mathrm{W}$ section indicates the strongest oxygen reduction above the core of the deep OMZ and north of the Cape Verde archipelago (Fig. 18). Such a regional pattern is most likely due to changes in the circulation pattern associated with forced ocean dynamics as well as with internal ocean dynamics. Time series of all available oxygen data of the ETNA OMZ (Fig. 19) indicate variations on interannual, decadal, and multidecadal timescales; the long-term trend of deoxygenation associated with anthropogenic climate change might not be the dominant signal on such a regional scale. Improvements in model ventilation physics by increased resolution and/or improved parameterisations will reduce errors in the simulated mean oxygen distribution and its variability, but at the same time will help to 
understand the climate sensitivity of OMZs better with regard to anthropogenic climate change.

Oxygen data from shipboard repeat hydrography and moored observations show substantial interannual variability (Fig. 8) and trend-like changes (Fig. 19). The continuation of such measurements is essential to be able to test different hypotheses for the driving mechanisms of oxygen changes in the ocean. Using idealised or process models, distinct observed variability patterns might be reproduced and attributed to circulation changes and/or changes in the water mass distribution associated with the AMOC, STCs, PDO, or ENSO. For ocean circulation models, the acquired data provide the basis for improving the physical system in coupled climate-biogeochemistry simulations to make projections of future oxygen evolution more reliable.

Acknowledgements. This study was funded by the Deutsche Forschungsgemeinschaft as part of Sonderforschungsbereich 754 "Climate-Biogeochemistry Interactions in the Tropical Ocean", through several research cruises with RV Meteor, RV Maria S. Merian, and RV L'Atalante, and by the Deutsche Bundesministerium für Bildung und Forschung (BMBF) as part of projects NORDATLANTIK (03F0605B, 03F0443B), RACE (03F0651B), SOPRAN (03F0462A, 03F0611A, 03F0662A), and AWA (01DG12073E). Moored velocity and oxygen observations were partly acquired in cooperation with the PIRATA project, and we would like to thank B. Bourlès, R. Lumpkin, C. Schmid, and G. Foltz for their help with mooring work and data sharing. We also thank J. Lübbecke, L. D. Bryant, and B. Dewitte for helpful discussions and comments on an earlier version of the manuscript. We thank the captains and crew of the RV Maria S. Merian, RV Meteor, RV Poseidon, and RV L'Atalante as well as our technical group for their help with the fieldwork.

Edited by: L. Levin

\section{References}

Ascani, F., Firing, E., Dutrieux, P., McCreary, J. P., and Ishida, A.: Deep equatorial ocean circulation induced by a forced-dissipated Yanai beam, J. Phys. Oceanogr., 40, 1118-1142, 2010.

Banyte, D., Tanhua, T., Visbeck, M., Wallace, D. W. R., Karstensen, J., Krahmann, G., Schneider, A., Stramma, L., and Dengler, M.: Diapycnal diffusivity at the upper boundary of the tropical North Atlantic oxygen minimum zone, J. Geophys. Res.-Oceans, 117, C09016, doi:10.1029/2011jc007762, 2012.

Banyte, D., Visbeck, M., Tanhua, T., Fischer, T., Krahmann, G., and Karstensen, J.: Lateral diffusivity from tracer release experiments in the tropical North Atlantic thermocline, J. Geophys. Res.-Oceans, 118, 2719-2733, 2013.

Barton, E. D.: The poleward undercurrent on the eastern boundary of the subtropical North Atlantic, in: Poleward flows along Eastern Ocean Boundaries, Lecture Note Series ed., edited by: Neshyba, S. J., Smith, R. L., and Mooers, C. N. K., SpringerVerlag, 82-95, 1989.
Belmadani, A., Echevin, V., Dewitte, B., and Colas, F.: Equatorially forced intraseasonal propagations along the Peru-Chile coast and their relation with the nearshore eddy activity in 19922000: A modeling study, J. Geophys. Res.-Oceans, 117, C04025, doi:10.1029/2011jc007848, 2012.

Bianchi, D., Galbraith, E. D., Carozza, D. A., Mislan, K. A. S., and Stock, C. A.: Intensification of open-ocean oxygen depletion by vertically migrating animals, Nat. Geosci., 6, 545-548, 2013.

Biastoch, A., Böning, C. W., Schwarzkopf, F. U., and Lutjeharms, J. R. E.: Increase in Agulhas leakage due to poleward shift of Southern Hemisphere westerlies, Nature, 462, 495-498, 2009.

Bolin, B. and Rodhe, H.: Note on Concepts of Age Distribution and Transit-Time in Natural Reservoirs, Tellus, 25, 58-62, 1973.

Bopp, L., Le Quere, C., Heimann, M., Manning, A. C., and Monfray, P.: Climate-induced oceanic oxygen fluxes: Implications for the contemporary carbon budget, Global Biogeochem. Cy., 16, doi:10.1029/2001gb001445, 2002.

Bourles, B., Lumpkin, R., McPhaden, M. J., Hernandez, F., Nobre, P., Campos, E., Yu, L. S., Planton, S., Busalacchi, A., Moura, A. D., Servain, J., and Trotte, J.: The PIRATA program: History, accomplishments, and future directions, B Am. Meteorol. Soc., 89, 1111-1125, 2008.

Brandt, P., Hormann, V., Bourles, B., Fischer, J., Schott, F. A., Stramma, L., and Dengler, M.: Oxygen tongues and zonal currents in the equatorial Atlantic, J. Geophys. Res.-Oceans, 113, C04012, doi:10.1029/2007jc004435, 2008.

Brandt, P., Hormann, V., Körtzinger, A., Visbeck, M., Krahmann, G., Stramma, L., Lumpkin, R., and Schmid, C.: Changes in the ventilation of the oxygen minimum zone of the tropical North Atlantic, J. Phys. Oceanogr., 40, 1784-1801, 2010.

Brandt, P., Funk, A., Hormann, V., Dengler, M., Greatbatch, R. J., and Toole, J. M.: Interannual atmospheric variability forced by the deep equatorial Atlantic Ocean, Nature, 473, 497-500, 2011.

Brandt, P., Greatbatch, R. J., Claus, M., Didwischus, S. H., Hormann, V., Funk, A., Hahn, J., Krahmann, G., Fischer, J., and Körtzinger, A.: Ventilation of the equatorial Atlantic by the equatorial deep jets, J. Geophys. Res.-Oceans, 117, C12015, 2012.

Canfield, D. E.: Organic Matter Oxidation in Marine Sediments, in: Interactions of C, N, P and S Biogeochemical Cycles and Global Change, edited by: Wollast, R., Mackenzie, F. T., and Chou, L., NATO ASI Series, Springer Berlin Heidelberg, 333-363, 1993.

Chaigneau, A., Dominguez, N., Eldin, G., Vasquez, L., Flores, R., Grados, C., and Echevin, V.: Near-coastal circulation in the Northern Humboldt Current System from shipboard ADCP data, J. Geophys. Res.-Oceans, 118, 5251-5266, 2013.

Chang, P., Zhang, R., Hazeleger, W., Wen, C., Wan, X. Q., Ji, L., Haarsma, R. J., Breugem, W. P., and Seidel, H.: Oceanic link between abrupt changes in the North Atlantic Ocean and the African monsoon, Nat. Geosci., 1, 444-448, 2008.

Chelton, D. B., Schlax, M. G., Samelson, R. M., and de Szoeke, R. A.: Global observations of large oceanic eddies, Geophys. Res. Lett., 34, L15606, doi:10.1029/2007g1030812, 2007.

Chelton, D. B., Schlax, M. G., and Samelson, R. M.: Global observations of nonlinear mesoscale eddies, Prog. Oceanogr., 91, 167-216, 2011.

Czeschel, R., Stramma, L., Schwarzkopf, F. U., Giese, B. S., Funk, A., and Karstensen, J.: Middepth circulation of the eastern tropical South Pacific and its link to the oxy- 
gen minimum zone, J. Geophys. Res.-Oceans, 116, C01015, doi:10.1029/2010jc006565, 2011.

Czeschel, R., Stramma, L., and Johnson, G. C.: Oxygen decreases and variability in the eastern equatorial Pacific, J. Geophys. Res.Oceans, 117, C11019, doi:10.1029/2012jc008043, 2012.

d'Orgeville, M., Hua, B. L., and Sasaki, H.: Equatorial deep jets triggered by a large vertical scale variability within the western boundary layer, J. Mar. Res., 65, 1-25, 2007.

Dale, A. W., Sommer, S., Ryabenko, E., Noffke, A., Bohlen, L., Wallmann, K., Stolpovsky, K., Greinert, J., and Pfannkuche, O.: Benthic nitrogen fluxes and fractionation of nitrate in the Mauritanian oxygen minimum zone (Eastern Tropical North Atlantic), Geochim. Cosmochim. Ac., 134, 234-256, 2014.

Davis, R. E.: Intermediate-depth circulation of the Indian and South Pacific Oceans measured by autonomous floats, J. Phys. Oceanogr., 35, 683-707, 2005.

Deutsch, C., Brix, H., Ito, T., Frenzel, H., and Thompson, L.: Climate-Forced Variability of Ocean Hypoxia, Science, 333, 336-339, 2011.

Deutsch, C., Berelson, W., Thunell, R., Weber, T., Tems, C., McManus, J., Crusius, J., Ito, T., Baumgartner, T., Ferreira, V., Mey, J., and van Geen, A.: Centennial changes in North Pacific anoxia linked to tropical trade winds, Science, 345, 665-668, 2014.

Duteil, O., Schwarzkopf, F. U., Böning, C. W., and Oschlies, A.: Major role of the equatorial current system in setting oxygen levels in the eastern tropical Atlantic Ocean: A high- resolution model study, Geophys. Res. Lett., 41, 2033-2040, 2014.

Eden, C.: Eddy length scales in the North Atlantic Ocean, J. Geophys. Res.-Oceans, 112, C06004, doi:10.1029/2006jc003901, 2007.

Eden, C. and Greatbatch, R. J.: A diagnosis of isopycnal mixing by mesoscale eddies, Ocean Model, 27, 98-106, 2009.

Ferrari, R. and Polzin, K. L.: Finescale structure of the T-S relation in the eastern North Atlantic, J. Phys. Oceanogr., 35, 1437-1454, 2005.

Fischer, T., Banyte, D., Brandt, P., Dengler, M., Krahmann, G., Tanhua, T., and Visbeck, M.: Diapycnal oxygen supply to the tropical North Atlantic oxygen minimum zone, Biogeosciences, 10, 5079-5093, doi:10.5194/Bg-10-5079-2013, 2013.

Frölicher, T. L., Joos, F., Plattner, G. K., Steinacher, M., and Doney, S. C.: Natural variability and anthropogenic trends in oceanic oxygen in a coupled carbon cycle-climate model ensemble, Global Biogeochem. Cy., 23, GB1003, doi:10.1029/2008gb003316, 2009.

Glud, R. N.: Oxygen dynamics of marine sediments, Mar. Biol. Res., 4, 243-289, 2008.

Gnanadesikan, A., Bianchi, D., and Pradal, M. A.: Critical role for mesoscale eddy diffusion in supplying oxygen to hypoxic ocean waters, Geophys. Res. Lett., 40, 5194-5198, 2013.

Gregg, M. C., Sanford, T. B., and Winkel, D. P.: Reduced mixing from the breaking of internal waves in equatorial waters, Nature, 422, 513-515, 2003.

Gutierrez, D., Enriquez, E., Purca, S., Quipuzcoa, L., Marquina, R., Flores, G., and Graco, M.: Oxygenation episodes on the continental shelf of central Peru: Remote forcing and benthic ecosystem response, Prog. Oceanogr., 79, 177-189, 2008.

Hagen, E.: Northwest African upwelling scenario, Oceanol. Acta, 24, 113-128, 2001.
Hahn, J., Brandt, P., Greatbatch, R. J., Krahmann, G., and Körtzinger, A.: Oxygen variance and meridional oxygen supply in the Tropical North East Atlantic oxygen minimum zone, Clim. Dynam., 43, 2999-3024, 2014.

Haine, T. W. N. and Hall, T. M.: A generalized transport theory: Water-mass composition and age, J. Phys. Oceanogr., 32, 19321946, 2002.

Helm, K. P., Bindoff, N. L., and Church, J. A.: Observed decreases in oxygen content of the global ocean, Geophys. Res. Lett., 38, L23602, doi:10.1029/2011g1049513, 2011.

Holloway, P. E.: A comparison of semidiurnal internal tides from different bathymetric locations on the Australian North-West Shelf, J. Phys. Oceanogr., 15, 240-251, 1985.

Holtappels, M., Tiano, L., Kalvelage, T., Lavik, G., Revsbech, N. P., and Kuypers, M. M. M.: Aquatic Respiration Rate Measurements at Low Oxygen Concentrations, Plos One, 9, e89369, doi:10.1371/journal.pone.0089369, 2014.

Hua, B. L., d'Orgeville, M., Fruman, M. D., Menesguen, C., Schopp, R., Klein, P., and Sasaki, H.: Destabilization of mixed Rossby gravity waves and the formation of equatorial zonal jets, J. Fluid Mech., 610, 311-341, 2008.

Ito, T. and Deutsch, C.: Variability of the oxygen minimum zone in the tropical North Pacific during the late twentieth century, Global Biogeochem. Cy., 27, 1119-1128, 2013.

Jenkins, W. J.: Oxygen Utilization Rates in North-Atlantic SubTropical Gyre and Primary Production in Oligotrophic Systems, Nature, 300, 246-248, 1982.

Jenkins, W. J.: Studying subtropical thermocline ventilation and circulation using tritium and He-3, J. Geophys. Res.-Oceans, 103, 15817-15831, 1998.

Jochum, M., Malanotte-Rizzoli, P., and Busalacchi, A.: Tropical instability waves in the Atlantic ocean, Ocean Model, 7, 145-163, 2004.

Kamenkovich, I., Berloff, P., and Pedlosky, J.: Anisotropic material transport by eddies and eddy-driven currents in a model of the North Atlantic, J. Phys. Oceanogr., 39, 3162-3175, 2009.

Karstensen, J., Stramma, L., and Visbeck, M.: Oxygen minimum zones in the eastern tropical Atlantic and Pacific oceans, Prog. Oceanogr., 77, 331-350, 2008.

Keeling, R. F. and Garcia, H. E.: The change in oceanic O-2 inventory associated with recent global warming, P. Natl. Acad. Sci. USA, 99, 7848-7853, 2002.

Keeling, R. F., Körtzinger, A., and Gruber, N.: Ocean deoxygenation in a warming world, Annu. Rev. Mar. Sci., 2, 199-229, 2010

Kessler, W. S.: The circulation of the eastern tropical Pacific: A review, Prog. Oceanogr., 69, 181-217, 2006.

Kirchner, K., Rhein, M., Hüttl-Kabus, S., and Böning, C. W.: On the spreading of South Atlantic Water into the Northern Hemisphere, J. Geophys. Res.-Oceans, 114, C05019, doi:10.1029/2008JC005165, 2009.

Lachkar, Z. and Gruber, N.: A comparative study of biological production in eastern boundary upwelling systems using an artificial neural network, Biogeosciences, 9, 293-308, doi:10.5194/Bg-9293-2012, 2012.

Ledwell, J. R., Watson, A. J., and Law, C. S.: Mixing of a tracer in the pycnocline, J. Geophys. Res.-Oceans, 103, 21499-21529, 1998.

Lu, Z. T., Schlosser, P., Smethie Jr, W. M., Sturchio, N. C., Fischer, T. P., Kennedy, B. M., Purtschert, R., Severinghaus, J. P., 
Solomon, D. K., Tanhua, T., and Yokochi, R.: Tracer applications of noble gas radionuclides in the geosciences, Earth-Sci. Rev., 138, 196-214, doi:10.1016/j.earscirev.2013.09.002, 2014.

Lutz, M., Dunbar, R., and Caldeira, K.: Regional variability in the vertical flux of particulate organic carbon in the ocean interior, Global Biogeochem. Cy., 16, 1037, doi:10.1029/2000gb001383, 2002.

Luyten, J., Pedlosky, J., and Stommel, H.: Climatic Inferences from the Ventilated Thermocline, Clim. Change, 5, 183-191, 1983 a.

Luyten, J. R., Pedlosky, J., and Stommel, H.: The ventilated thermocline, J. Phys. Oceanogr., 13, 292-309, 1983 b.

Machin, F. and Pelegri, J. L.: Northward penetration of Antarctic Intermediate Water off Northwest Africa, J. Phys. Oceanogr., 39, 512-535, 2009.

Malanotte-Rizzoli, P., Hedstrom, K., Arango, H., and Haidvogel, D. B.: Water mass pathways between the subtropical and tropical ocean in a climatological simulation of the North Atlantic ocean circulation, Dynam. Atmos. Oceans., 32, 331-371, 2000.

Martin, J. H., Knauer, G. A., Karl, D. M., and Broenkow, W. W.: Vertex - carbon cycling in the Northeast Pacific, Deep-Sea Res. Pt. A, 34, 267-285, 1987.

Martz, T. R., Johnson, K. S., and Riser, S. C.: Ocean metabolism observed with oxygen sensors on profiling floats in the South Pacific, Limnol. Oceanogr., 53, 2094-2111, 2008

Matear, R. J. and Hirst, A. C.: Long-term changes in dissolved oxygen concentrations in the ocean caused by protracted global warming, Global Biogeochem. Cy., 17, 1125, doi:10.1029/2002gb001997, 2003.

Maximenko, N. A., Bang, B., and Sasaki, H.: Observational evidence of alternating zonal jets in the world ocean, Geophys. Res. Lett., 32, L12607, doi:10.1029/2005g1022728, 2005.

McCreary, J. P., Yu, Z. J., Hood, R. R., Vinaychandran, P. N., Furue, R., Ishida, A., and Richards, K. J.: Dynamics of the Indian-Ocean oxygen minimum zones, Prog. Oceanogr., 112, 15-37, 2013.

Ménesguen, C., Hua, B. L., Fruman, M. D., and Schopp, R.: Dynamics of the combined extra-equatorial and equatorial deep jets in the Atlantic, J. Mar. Res., 67, 323-346, 2009.

Mittelstaedt, E.: The upwelling area off Northwest Africa - a description of phenomena related to coastal upwelling, Prog. Oceanogr., 12, 307-331, 1983.

Mittelstaedt, E.: The ocean boundary along the Northwest African Coast - circulation and oceanographic properties at the seasurface, Prog. Oceanogr., 26, 307-355, 1991.

Monteiro, P. M. S., Dewitte, B., Scranton, M. I., Paulmier, A., and van der Plas, A. K.: The role of open ocean boundary forcing on seasonal to decadal-scale variability and long-term change of natural shelf hypoxia, Environ. Res. Lett., 6, 025002, doi:10.1088/1748-9326/6/2/025002, 2011.

Montes, I., Dewitte, B., Gutknecht, E., Paulmier, A., Dadou, I., Oschlies, A., and Garcon, V.: High-resolution modeling of the Eastern Tropical Pacific oxygen minimum zone: Sensitivity to the tropical oceanic circulation, J. Geophys. Res.-Oceans, 119, 5515-5532, 2014.

Ollitrault, M., Lankhorst, M., Fratantoni, D., Richardson, P., and Zenk, W.: Zonal intermediate currents in the equatorial Atlantic Ocean, Geophys. Res. Lett., 33, L05605, doi:10.1029/2005g1025368, 2006.

Oschlies, A., Schulz, K. G., Riebesell, U., and Schmittner, A.: Simulated 21st century's increase in oceanic suboxia by $\mathrm{CO}_{2}$ - enhanced biotic carbon export, Global Biogeochem. Cy., 22, GB4008, doi:10.1029/2007gb003147, 2008.

Peña-Izquierdo, J., Pelegri, J. L., Pastor, M. V., Castellanos, P., Emelianov, M., Gasser, M., Salvador, J., and VazquezDominguez, E.: The continental slope current system between Cape Verde and the Canary Islands, Sci. Mar., 76, 65-78, 2012.

Plattner, G. K., Joos, F., and Stocker, T. F.: Revision of the global carbon budget due to changing air-sea oxygen fluxes, Global Biogeochem. Cy., 16, 1096, doi:10.1029/2001gb001746, 2002.

Polo, I., Lazar, A., Rodriguez-Fonseca, B., and Arnault, S.: Oceanic Kelvin waves and tropical Atlantic intraseasonal variability: 1. Kelvin wave characterization, J. Geophys. Res.-Oceans, 113, C07009, doi:10.1029/2007jc004495, 2008.

Qiu, B., Chen, S. M., and Sasaki, H.: Generation of the North Equatorial Undercurrent jets by triad baroclinic Rossby wave interactions, J. Phys. Oceanogr., 43, 2682-2698, 2013.

Rabe, B., Schott, F. A., and Kohl, A.: Mean circulation and variability of the tropical Atlantic during 1952-2001 in the GECCO assimilation fields, J. Phys. Oceanogr., 38, 177-192, 2008.

Riley, G. A.: Oxygen, phosphate, and nitrate in the Atlantic Ocean, Bull. Bingham. Oceanogr. Coll., 12, 1-126, 1951.

Roether, W., Jean-Baptiste, P., Fourre, E., and Sultenfuss, J.: The transient distributions of nuclear weapon-generated tritium and its decay product He-3 in the Mediterranean Sea, 1952-2011, and their oceanographic potential, Ocean Sci., 9, 837-854, 2013 , http://www.ocean-sci.net/9/837/2013/.

Sandstrom, H. and Oakey, N. S.: Dissipation in internal tides and solitary waves, J. Phys. Oceanogr., 25, 604-614, 1995.

Schafstall, J., Dengler, M., Brandt, P., and Bange, H.: Tidalinduced mixing and diapycnal nutrient fluxes in the Mauritanian upwelling region, J. Geophys. Res.-Oceans, 115, C10014, doi:10.1029/2009jc005940, 2010.

Schmidtko, S., Johnson, G. C., and Lyman, J. M.: MIMOC: A global monthly isopycnal upper-ocean climatology with mixed layers, J. Geophys. Res.-Oceans, 118, 1658-1672, 2013.

Schmittner, A., Oschlies, A., Matthews, H. D., and Galbraith, E. D.: Future changes in climate, ocean circulation, ecosystems, and biogeochemical cycling simulated for a business-as-usual $\mathrm{CO}_{2}$ emission scenario until year $4000 \mathrm{AD}$, Global Biogeochem. Cy., 22, GB1013, doi:10.1029/2007gb002953, 2008.

Schneider, A., Tanhua, T., Körtzinger, A., and Wallace, D. W. R.: An evaluation of tracer fields and anthropogenic carbon in the equatorial and the tropical North Atlantic, Deep-Sea Res. Pt. I, 67, 85-97, 2012.

Schott, F. A., Stramma, L., and Fischer, J.: The warm water inflow into the western tropical Atlantic boundary regime, spring 1994, J. Geophys. Res.-Oceans, 100, 24745-24760, 1995.

Schott, F. A., Fischer, J., and Stramma, L.: Transports and pathways of the upper-layer circulation in the western tropical Atlantic, J. Phys. Oceanogr., 28, 1904-1928, 1998.

Schott, F. A., McCreary, J. P., and Johnson, G. C.: Shallow overturning circulations of the tropical-subtropical oceans, in: Earth Climate: The Ocean-Atmosphere Interaction, edited by: Wang, C., Xie, S.-P., and Carton, J. A., Geophysical Monograph 147, American Geophysical Union, Washington, DC, 261-304, 2004.

Schott, F. A., Dengler, M., Zantopp, R., Stramma, L., Fischer, J., and Brandt, P.: The shallow and deep western boundary circulation of the South Atlantic at $5^{\circ}-11^{\circ} \mathrm{S}$, J. Phys. Oceanogr., 35, 2031-2053, 2005. 
St. Laurent, L. and Schmitt, R. W.: The contribution of salt fingers to vertical mixing in the North Atlantic Tracer Release Experiment, J. Phys. Oceanogr., 29, 1404-1424, 1999.

Stanley, R. H. R., Doney, S. C., Jenkins, W. J., and Lott, D. E.: Apparent oxygen utilization rates calculated from tritium and helium-3 profiles at the Bermuda Atlantic Time-series Study site, Biogeosciences, 9, 1969-1983, doi:10.5194/Bg-9-1969-2012, 2012.

Stendardo, I. and Gruber, N.: Oxygen trends over five decades in the North Atlantic, J. Geophys. Res.-Oceans, 117, C11004, doi:10.1029/2012jc007909, 2012.

Stramma, L. and England, M. H.: On the water masses and mean circulation of the South Atlantic Ocean, J. Geophys. Res.Oceans, 104, 20863-20883, 1999.

Stramma, L., Brandt, P., Schafstall, J., Schott, F., Fischer, J., and Körtzinger, A.: Oxygen minimum zone in the North Atlantic south and east of the Cape Verde Islands, J. Geophys. Res.Oceans, 113, C04014, doi:10.1029/2007jc004369, 2008a.

Stramma, L., Johnson, G. C., Sprintall, J., and Mohrholz, V.: Expanding oxygen-minimum zones in the tropical oceans, Science, 320, 655-658, 2008b.

Stramma, L., Visbeck, M., Brandt, P., Tanhua, T., and Wallace, D.: Deoxygenation in the oxygen minimum zone of the eastern tropical North Atlantic, Geophys. Res. Lett., 36, L20607, doi:10.1029/2009g1039593, 2009.

Stramma, L., Johnson, G. C., Firing, E., and Schmidtko, S.: Eastern Pacific oxygen minimum zones: Supply paths and multidecadal changes, J. Geophys. Res.-Oceans, 115, C09011, doi:10.1029/2009jc005976, 2010a.

Stramma, L., Schmidtko, S., Levin, L. A., and Johnson, G. C.: Ocean oxygen minima expansions and their biological impacts, Deep-Sea Res. Pt. I, 57, 587-595, 2010 b.

Stramma, L., Oschlies, A., and Schmidtko, S.: Mismatch between observed and modeled trends in dissolved upper-ocean oxygen over the last $50 \mathrm{yr}$, Biogeosciences, 9, 4045-4057, doi:10.5194/Bg-9-4045-2012, 2012.

Stramma, L., Bange, H. W., Czeschel, R., Lorenzo, A., and Frank, M.: On the role of mesoscale eddies for the biological productivity and biogeochemistry in the eastern tropical Pacific Ocean off Peru, Biogeosciences, 10, 7293-7306, doi:10.5194/Bg-10-72932013, 2013.

Stramma, L., Weller, R. A., Czeschel, R., and Bigorre, S.: Eddies and an extreme water mass anomaly observed in the eastern south Pacific at the Stratus mooring, J. Geophys. Res. Oceans, 119, 1068-1083, 2014.
Suga, T. and Talley, L. D.: Antarctic intermediate water circulation in the tropical and subtropical South-Atlantic, J. Geophys. Res.Oceans, 100, 13441-13453, 1995.

Sverdrup, H. U.: On the Explanation of the Oxygen Minima and Maxima in the Oceans, Journal du Conseil, 13, 163-172, 1938.

Tatebe, H., Imada, Y., Mori, M., Kimoto, M., and Hasumi, H.: Control of Decadal and Bidecadal Climate Variability in the Tropical Pacific by the Off-Equatorial South Pacific Ocean, J. Climate, 26, 6524-6534, 2013.

Thiele, G. and Sarmiento, J. L.: Tracer Dating and Ocean Ventilation, J. Geophys. Res.-Oceans, 95, 9377-9391, 1990.

Tsuchiya, M.: Thermostats and circulation in the upper layer of the Atlantic Ocean, Prog. Oceanogr., 16, 235-267, 1986.

Tsuchiya, M., Talley, L. D., and Mccartney, M. S.: An eastern Atlantic section from Iceland southward across the equator, DeepSea Res. Pt. A, 39, 1885-1917, 1992.

von Schuckmann, K., Brandt, P., and Eden, C.: Generation of tropical instability waves in the Atlantic Ocean, J. Geophys. Res.Oceans, 113, C08034, doi:10.1029/2007jc004712, 2008.

Wattenberg, H.: Die Verteilung des Sauerstoffs im Atlantischen Ozean, Wissenschaftliche Ergebnisse der Deutschen Atlantischen Expedition auf dem Forschungs- und Vermessungsschiff Meteor 1925-1927, 9.1, edited by: Defant, A., de Gruyter, Berlin, Leipzig, 132 pp., 1938.

Waugh, D. W., Haine, T. W. N., and Hall, T. M.: Transport times and anthropogenic carbon in the subpolar North Atlantic Ocean, Deep-Sea Res. Pt. I, 51, 1475-1491, 2004.

Weiss, R. F.: Solubility of Nitrogen, Oxygen and Argon in Water and Seawater, Deep-Sea Res., 17, 721-735, 1970.

Wollast, R.: Evaluation and comparison of the global carbon cycle in the coastal zone and in the open ocean, in: The Sea, edited by: Robinson, A., Brink, K. H., Wiley, New York, 213-252, 1998.

Wüst, G.: Die Stratosphäre des Atlantischen Ozeans, Deutsche Atlantische Exped, Meteor 1925-1927, Wiss. Erg., 6, 288 pp., 1935.

Wyrtki, K.: The oxygen minima in relation to ocean circulation, Deep-Sea Res., 9, 11-23,1962.

Zhang, D. X., McPhaden, M. J., and Johns, W. E.: Observational evidence for flow between the subtropical and tropical Atlantic: The Atlantic subtropical cells, J. Phys. Oceanogr., 33, 17831797, 2003.

Zilberman, N. V., Roemmich, D. H., and Gille, S. T.: The Mean and the Time Variability of the Shallow Meridional Overturning Circulation in the Tropical South Pacific Ocean, J. Climate, 26, 4069-4087, 2013. 